\title{
DAXX safeguards pericentromeric heterochromatin formation in embryonic stem cells
}

Authors: Antoine Canat (1,2), Adeline Veillet (1), Robert Illingworth (3), Emmanuelle Fabre (1), Pierre Therizols $(1)^{*}$

\section{Affiliation:}

(1) Université de Paris, Laboratoire Génomes, Biologie Cellulaire et Thérapeutiques, CNRS UMR7212, INSERM U944, Institut de Recherche St Louis, F- 75010 Paris, France

(2) Present address: Institute of Epigenetics and Stem Cells, Helmholtz Zentrum München, München, Germany

(3) Centre for Regenerative Medicine, Institute for Regeneration and Repair, The University of Edinburgh, Edinburgh BioQuarter, 5 Little France Drive, Edinburgh EH16 4UU, United Kingdom.

*Correspondence: pierre.therizols@inserm.fr. Tel: +33-1-5372-4058 


\section{Abstract}

DNA methylation is essential for heterochromatin formation and repression of DNA repeat transcription, both of which are essential for genome integrity. Loss of DNA methylation is associated with disease, including cancer, but is also required for development. Alternative pathways to maintain heterochromatin are thus needed to limit DNA damage accumulation. Here, we find that DAXX, an $\mathrm{H} 3.3$ chaperone, protects pericentromeric heterochromatin and is essential for embryonic stem cells (ESCs) maintenance in the ground-state of pluripotency. Upon DNA demethylation-mediated damage, DAXX relocalizes to pericentromeric regions, and recruits PML and SETDB1, thereby promoting heterochromatin formation. In the absence of DAXX, the 3D-architecture and physical properties of pericentric heterochromatin are disrupted, resulting in derepression of major satellite DNA. Using epigenome editing tools, we demonstrate that $\mathrm{H} 3.3$, and specifically $\mathrm{H} 3.3 \mathrm{~K} 9$ modification, directly contribute to maintaining pericentromeric chromatin conformation. Altogether, our data reveal that DAXX and $\mathrm{H} 3.3$ unite DNA damage response and heterochromatin maintenance in ESCs.

Keywords: Heterochromatin, Pericentromere, Chromocenters, histone variant H3.3, DAXX, SETDB1, DNA damage, Embryonic Stem Cell, Ground-state of pluripotency 


\section{Introduction}

Mammalian genomes contain major regions of repetitive DNA, with satellites comprising one of the most abundant classes. In mouse, pericentromeric regions are composed of major satellites comprising tandem repeats of a $234 \mathrm{bp}$ sequence that constitute approximately $8 \mathrm{Mb}$ on each chromosome (Guenatri et al., 2004; Mouse Genome Sequencing Consortium et al., 2002). These regions are ordinarily repressed, and transcriptional activation of DNA repeats and pericentromeric satellites is a hallmark of cancer transformation and various other diseases (Corless et al., 2020). Pericentromeric silencing is therefore crucial to protect genome integrity and cell identity. Most repeated sequences are transcriptionally repressed by cooperative epigenetic mechanisms leading to the formation of constitutive heterochromatin. At the molecular level, constitutive heterochromatin exhibits covalent modifications including DNA methylation and/ or $\mathrm{H} 3 \mathrm{~K} 9$ and $\mathrm{H} 4 \mathrm{~K} 20$ trimethylation (H3K9me3 and H4K20me3). Maintenance of $\mathrm{H} 3 \mathrm{~K} 9 \mathrm{me} 3$ at pericentromeric satellites relies on the SUV39H1/2 methyltransferases, whereas a distinct H3K9me3 methyltransferase, SETDB1, operates at dispersed DNA repeats and telomeres (Fukuda et al., 2018; Martens et al., 2005; Matsui et al., 2010). The three-dimensional organization of heterochromatin is another important layer regulating DNA repeat transcription (Falk et al., 2019; Lu et al., 2021). In some species, including the mouse, the pericentromeric heterochromatin $(\mathrm{PCH})$ of different chromosomes aggregates to form large DAPI-dense heterochromatin clusters, called chromocenters. Disruption of satellite clustering is often associated with increased DNA damage and defects in chromosome segregation that are seen in pathologies including Alzheimer's disease and breast cancer (Hahn et al., 2013; Jagannathan et al., 2018; Mansuroglu et al., 2016; Zhu et al., 2011).

Preimplantation embryogenesis is a critical step in heterochromatin establishment. DNA methylation is reset and reaches its minimal level in the blastocyst. At this stage, cells from the inner cell mass are free of epigenetic restriction, and referred to as ground-state pluripotent 
stem cells (Leitch et al., 2013; Ying et al., 2008). The wave of DNA demethylation leads to the transcriptional upregulation of several repetitive sequences, a process that is essential for normal embryogenesis (Jachowicz et al., 2017; Probst et al., 2010). At the 2-cell stage, upregulation of major satellite transcripts is required for $\mathrm{PCH}$ reorganization into chromocenters and normal developmental progression (Casanova et al., 2013; Probst et al., 2010). However, derepression of DNA repeats correlates with high DNA damage signaling and prolonged expression results in developmental arrest, suggesting that silencing through a DNA methylation-independent mechanism is required for normal embryogenesis (Jachowicz et al., 2017; Ziegler-Birling et al., 2009). Polycomb group proteins were previously shown to bind and facilitate silencing of repetitive sequences upon DNA hypomethylation (Saksouk et al., 2014; Tosolini et al., 2018; Walter et al., 2016). However, knockout of most polycomb-related genes does not impair ESC self-renewal or impact pre-implantation embryogenesis (Aloia et al., 2013), implying that other factors maintain heterochromatin in the absence of DNA methylation.

The histone variant $\mathrm{H} 3.3$ is associated with DNA repeats and might therefore contribute to heterochromatin reorganization. H3.3 differs from the canonical histone H3 by 4 or 5 residues and is deposited, independently of DNA synthesis, in both active and inactive chromatin (Szenker et al., 2011). Specific sites of incorporation are determined by a histone chaperone, a histone-binding protein that prevents promiscuous deposition into chromatin. Together with ATRX, DAXX forms a histone chaperone complex responsible for H3.3 incorporation into heterochromatin regions, including $\mathrm{PCH}$, retrotransposons and telomeres (Elsässer et al., 2015; He et al., 2015; Lewis et al., 2010; Sadic et al., 2015). DAXX is a known partner of PML found in membrane-less nuclear bodies that form hubs for post-translational modification of proteins (Lallemand-Breitenbach and de Thé, 2018). DAXX binds major satellite regions during the earliest stages of development, just before $\mathrm{PCH}$ reorganizes to form chromocenters (Arakawa et al., 2015; Liu et al., 2020). While the importance of DAXX for chromocenter formation remains unknown, most Daxx ${ }^{-/-}$embryos fail to reach the pluripotent stage that 
directly follows chromocenter formation (Liu et al., 2020), suggesting a direct link between DAXX function at chromocenters and developmental progression.

Here, we decipher the role played by DAXX at PCH in pluripotent embryonic stem cells (ESCs). We find that DAXX is essential for ground-state ESC survival. Furthermore, we provide evidence that DAXX localizes to pericentric heterochromatin and recruits SETDB1, facilitating heterochromatin formation and organization through H3.3K9 modification. DAXX recruitment to $\mathrm{PCH}$ is triggered by an elevated DNA damage response initiated, at least in part, by active DNA demethylation. Thus, our results identify DAXX as a link between the DNA damage response and constitutive heterochromatin formation and maintenance.

\section{Results}

\section{DAXX is essential for ESC survival upon ground-state conversion.}

To assess the role of DAXX in pluripotent cells, we generated a Daxx knock-out (KO) ESC line. We targeted exon 3 of Daxx using CRISPR/cas9 technology and confirmed the absence of DAXX mRNA and protein (Figure 1A). There were no obvious changes in $\mathrm{H} 3.3$ protein levels in the resulting Daxx KO ESC line (Figure 1A). Consistent with previous reports, loss of DAXX did not impact the growth of ESCs cultured with a serum-based medium (Elsässer et al., 2015). Likewise, withdrawing leukemia inhibitory factor and adding retinoic acid had no impact on cellular viability in Daxx KO ESC during neuronal differentiation (Figure 1B). Under serum conditions, ESCs have higher levels of DNA methylation than the blastocyst cells from which they are derived (Borgel et al., 2010). In contrast, ESCs cultured in a medium with two small kinase inhibitors and vitamin $\mathrm{C}$ (hereafter denoted $2 \mathrm{i}+\mathrm{VitC}$ ), exhibit very low levels of DNA methylation, as the cells are transitioned to the ground-state of pluripotency (Blaschke et al., 2013). To evaluate the role of DAXX in ground-state ESCs, Daxx KO and WT ESCs were converted to this state using $2 \mathrm{i}+\mathrm{VitC}$. We confirmed that DNA methylation levels were reduced in both cell lines under these conditions (Figure 1C). While no growth defect was detected for Daxx KO cells after 4 days of conversion, prolonged culture in $2 \mathrm{i}+\mathrm{VitC}$ medium induced a 
drastic decrease in cell viability (Figure 1B). Compared to the parental WT line, only $12.6 \%$ of Daxx KO ESCs remained after 8 days of culture in $2 i+V i t C$ (Figure 1B). No surviving cells could be detected after 9 to 10 days of conversion. These results indicate an essential role for DAXX in the maintenance of pluripotent cell survival upon ground-state conversion.

To further investigate the impact of Daxx knockout, we monitored the transcriptional landscapes under different conditions using RNA sequencing (RNA-seq). Daxx KO and WT cells show only negligible differential expression of protein coding genes and repeated elements upon differentiation with retinoic acid (Figure S1A, S1B, S1C). We concluded that the absence of DAXX only has a minor impact on transcriptome changes upon neuronal differentiation. This result is consistent with the absence of morphological or cell growth defects observed upon differentiation and confirms that DAXX is dispensable for neuronal differentiation. In contrast, $2 \mathrm{i}+\mathrm{VitC}$ conversion resulted in substantial differential expression of genes in Daxx KO and WT ESCs (Figure S1B). However, the global transcriptional response of Daxx KO ESCs to $2 \mathrm{i}+\mathrm{VitC}$ medium was similar to WT ESCs (Figure S1A). We compared the expression of 166 markers previously identified as differentially expressed upon $2 i+V i t C$ conversion (Blaschke et al., 2013). For both cell lines the majority of these markers changed expression upon conversion according to the expected pattern (Figure 1D). We conclude that Daxx KO ESCs can reach the ground-state of pluripotency in $2 \mathrm{i}+\mathrm{VitC}$ and that their loss in viability was not caused by a conversion defect. We also found that many endogenous retrovirus families were upregulated in Daxx KO ESCs in serum and 2i+VitC (Figure S1C, S1D), consistent with previous observations (Elsässer et al., 2015; He et al., 2015). Several LINE1 elements, notably the L1MdT and L1MdA families, not previously reported as DAXX targets, were also upregulated in pluripotent Daxx KO ESCs (Figure S1C, S1D). The role of DAXX on transcriptional silencing was not limited to interspersed repeats as we detected a strong upregulation of major satellites RNA in both serum and $2 \mathrm{i}+\mathrm{VitC}$ condition in the Daxx KO cells (Figure S1C, S1D). 
Overall, our data show that Daxx is essential for survival of ground-state embryonic stem cells and facilitates the transcriptional repression of different classes of repeated elements.

\section{DAXX relocates to chromocenters after DNA damage upon ground-state conversion.}

To better characterize the role of DAXX in ground-state ESCs, we assessed its localization by immunofluorescence. DAXX formed round foci with a mean diameter of $0.35 \mu \mathrm{m}$ which colocalized with PML under all conditions (Figure 2A, S2A). Upon 2i+VitC conversion, DAXX also colocalized with DAPI-bright foci, surrounded by PML, albeit forming larger nuclear bodies of $1.1 \mu \mathrm{m}$ in diameter (Figure 2A, S2A). These atypical nuclear bodies contained both major satellite sequences and $\mathrm{H} 3 \mathrm{~K} 9 \mathrm{me} 3$ signal indicating that they formed at $\mathrm{PCH}$ (Figure S2B). In fact, DAXX and PML colocalized with chromocenters in half of ESCs grown in 2i+VitC (Figure 2B). Amongst those cells, $62 \%$ displayed only one chromocenter marked by DAXX, with 2 or 3 chromocenters marked per nucleus in the remaining cells. We conclude that upon $2 i+V i t C$ conversion, DAXX relocalizes to PCH in ground-state ESCs.

Given that chromocenters replicate synchronously during mid-S phase (Guenatri et al., 2004), the recruitment of DAXX to a subset of them cannot result from replicative chromatin remodeling. Since DAXX can contribute to chromatin remodeling upon DNA repair (Juhász et al., 2018), we addressed whether its recruitment to $\mathrm{PCH}$ in $2 \mathrm{i}+\mathrm{VitC}$ could result from DNA damage. We analyzed the accumulation of phosphorylated H2A.X histone variant (hereafter denoted as $\mathrm{yH} 2 \mathrm{AX}$ ), a marker of the DNA damage response, by counting the number of $\mathrm{yH} 2 \mathrm{AX}$ positive foci overlapping with chromocenters. We observed that the presence of $\mathrm{yH} 2 \mathrm{AX}$ foci at chromocenters anticorrelated with the level of cell differentiation. Nearly $60 \%$ of the cells presented at least one chromocenter marked with $\mathrm{yH} 2 \mathrm{AX}$ signal in $2 \mathrm{i}+\mathrm{VitC}$ and this fraction decreased to $45 \%$ in serum and to $29 \%$ in differentiated cells (Figure $2 \mathrm{C}$ ). Hence, the presence of DAXX at chromocenters in $2 \mathrm{i}+\mathrm{VitC}$ correlates with a higher DNA damage response. DaxX KO ESCs displayed the same levels of pericentric $\mathrm{YH} 2 \mathrm{AX}$ accumulation as WT ESCs 
suggesting that the absence of DAXX did not cause any additional damage accumulation at chromocenters (Figure S2C).

To investigate whether DAXX accumulation at chromocenters is caused by DNA damage, we treated the cells with Hydroxy-urea $(\mathrm{HU})$, a drug that provokes replication fork collapse generating double-strand breaks (DSBs) and thus $\mathrm{yH} 2 \mathrm{AX}$ accumulation (Figure S2D). HU treatment of $2 \mathrm{i}+\mathrm{VitC}$ ESCs significantly increased the fraction of cells displaying DAXX and PML accumulation at DAPI-rich foci to nearly $80 \%$ (Figure $2 \mathrm{~A}, 2 \mathrm{~B}$ ). The number of DAXX positive chromocenters per nucleus was also higher in treated cells, with a third of the cells showing more than 3 structures, compared to only $7 \%$ in untreated ground-state cells (Figure 2B). To address the specificity of DAXX relocalisation in response to DNA damage at this specific cell-stage, serum-grown and differentiated ESCs were also treated with HU. While HU treatment of differentiated cells had no significant impact on DAXX localization, $35 \%$ of treated serum-grown ESCs presented an accumulation of DAXX-PML at chromocenters (Figure 2B). These results indicate that DAXX relocates to $\mathrm{PCH}$ upon DNA damage specifically in pluripotent ESCs.

To confirm that DAXX recruitment to chromocenters arises from damage to major satellite sequences, we used CRISPR-Cas9 technology to specifically induce DSBs within PCH. As a control, we used a catalytically dead Cas9 mutant (dCas9), which had no significant impact on YH2AX and DAXX-PML signals (Figure S2E, 2D). In contrast, targeting Cas9 to major satellite repeats using a specific sgRNA caused efficient pericentromeric DSB formation, as determined by the accumulation of $\mathrm{yH} 2 \mathrm{AX}$ at chromocenters (Figure S2E). These induced $\mathrm{PCH}$ localized DSBs triggered DAXX-PML relocalization to chromocenters in $23 \%$ of the cells (Figure 2D).

These data indicate that ground-state ESCs show higher levels of DNA damage at major satellites and this results in DAXX recruitment to $\mathrm{PCH}$ within atypical PML nuclear bodies. 


\section{Active DNA demethylation causes DNA damage in embryonic stem cells}

Upon $2 \mathrm{i}+\mathrm{VitC}$ conversion, the level of DNA methylation at major satellites is particularly impacted (Leitch et al., 2013; Tosolini et al., 2018). To test whether the loss of DNA methylation leads to DAXX relocation to $\mathrm{PCH}$, we supplemented the serum-based medium with $2 \mu \mathrm{M} 5$ azacytidine, a specific inhibitor of the DNA methyltransferase enzymes (DNMTs). Interestingly, 5-azacytidine treatment of ESCs showed striking similarities to $2 \mathrm{i}+\mathrm{VitC}$ conversion. First, $\sim 30 \%$ of the treated cells formed atypical DAXX-PML nuclear bodies at chromocenters (Figure 3A). Second, cell survival was impaired upon 4 days of 5-azacytidine treatment in Daxx KO ESCs (Figure 3B). These results support our previous observations, suggesting a crucial role for DAXX in 2i+VitC medium when ESCs are hypomethylated.

Since active DNA demethylation via the TET enzymes can ultimately result in DSBs (Nakatani et al., 2015), we tested whether DNA demethylation is directly responsible for the additional damage observed at chromocenters during $2 \mathrm{i}+\mathrm{VitC}$ treatment. Following the design of a previous study (Miyanari et al., 2013), we generated a TALE (transcription activator-like effector) protein, engineered to specifically target major satellite sequences (hereafter called

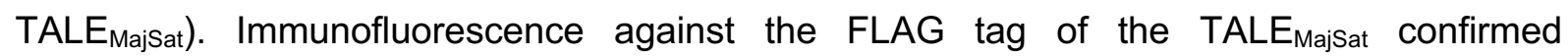
colocalization with chromocenters (Figure 3 C). To perform targeted DNA demethylation, we fused the TALE $E_{\text {MajSat }}$ to the catalytic domain of the TET1 enzyme (TET1CD) that converts 5methyl-cytosine $(5 \mathrm{mC})$ to 5-hydroxymethyl-cytosine (5hmC) (Maeder et al., 2013). Targeting of TET1CD to major satellites induced a $30 \%$ reduction in $5 \mathrm{mC}$ signal at chromocenters and led to increased levels of major satellite transcripts, but not other repeats such as IAPEz,

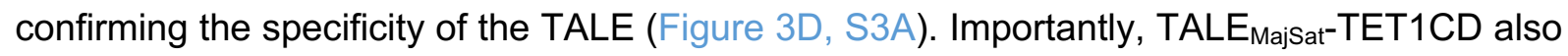
drastically increased pericentric $\mathrm{yH} 2 \mathrm{AX}$ foci. Nearly half of TALE $\mathrm{MajSat}-\mathrm{TET} 1 \mathrm{CD}$ transfected cells showed $\geq 4$ Flag-marked chromocenters containing $\mathrm{yH} 2 \mathrm{AX}$ foci, compared to only $3 \%$ in

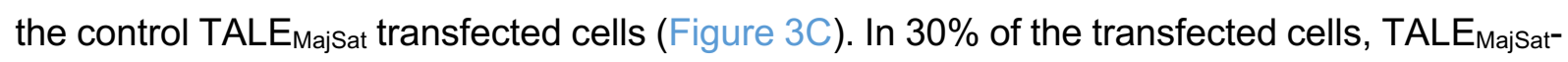
TET1CD also induced the formation of atypical PML at chromocenters (Figure S3B), similar to those observed after Cas9 or HU mediated DSBs (Figure 2A, 2D). We therefore conclude that 
DNA damage caused by TALE $\mathrm{MajSat}-\mathrm{TET} 1 \mathrm{CD}$ is directly responsible for the formation of atypical nuclear bodies at PCH. Together, our data support a model where active DNA methylation at major satellites causes DNA damage resulting in DAXX recruitment to chromocenters in ESCs upon $2 \mathrm{i}+\mathrm{VitC}$ conversion.

\section{DAXX maintains pericentric heterochromatin organization in pluripotent cells.}

DAXX deletion impaired the transcriptional repression of major satellites in pluripotent stem cells (Figure S1C, S1D). Since the loss of pericentromeric silencing is generally caused by defective heterochromatin assembly and often correlates with impaired clustering of chromocenters (Hahn et al., 2013; Healton et al., 2020; Pinheiro et al., 2012; Zhu et al., 2011), we next investigated whether DAXX facilitates $\mathrm{PCH}$ formation in ESCs. We performed DNA FISH experiments against the major satellites and counted the number of foci. In the absence of DAXX, the number of chromocenters was increased in both serum and $2 i+V i t C$ ESCs (Figure 4A). The increase in the number of foci detected in Daxx KO pluripotent ESCs correlated with a decrease in the size of major satellites foci (Figure S4A). The presence of an increased number of smaller chromocenters indicates that DAXX is required for their clustering in pluripotent ESCs. However, this role of DAXX is specific to pluripotent cells, as the deletion of Daxx had no detectible impact on the number and the size of major satellite foci upon neuronal differentiation (Figure S4A, S4B). The absence of a chromocenter clustering defect in differentiated Daxx KO cells is consistent with the reestablishment of major satellite silencing observed in these cells (Figure S1B, S1C). To confirm that DAXX could directly affect

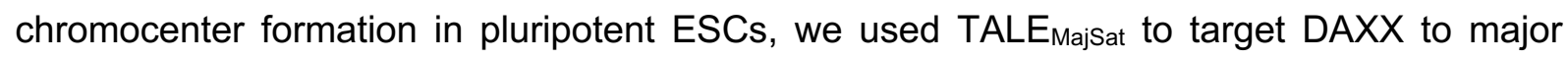

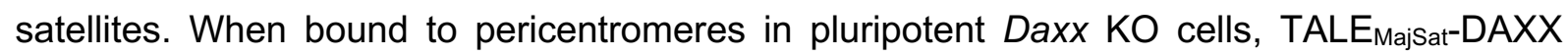
restored chromocenter clustering with the formation of larger and fewer PCH foci (Figure 4B). In WT ESCs, artificial tethering of DAXX to chromocenters had a similar impact and enhanced endogenous chromocenter clustering (Figure S4C). We conclude that DAXX enhances physical interactions between major satellites and contributes to the 3D-organization of $\mathrm{PCH}$. 
We hypothesized that the decreased chromocenter clustering seen in Daxx KO ESCs might result from defective heterochromatin formation. Functional heterochromatin forms a selfsegregating subcompartment with limited protein exchange with the rest of the nucleoplasm (Hinde et al., 2015; Strom et al., 2017). To test whether DAXX is important for heterochromatin segregation, we followed GFP-HP1a using live-imaging in WT and Daxx KO ESCs (Figure 4C). We monitored the mobility of GFP-HP1 1 by measuring the fluorescence recovery rate of GFP-HP1 $\alpha$ bound at chromocenters after photobleaching (Figure 4C, S4D). Compared to WT, the half-recovery time was significantly shorter in the absence of DAXX both in serum and ground-state conditions, implying a higher protein exchange between chromocenter and the nucleoplasm in Daxx KO cells (Figure 4C). However, the mobile fraction of GFP-HP1a remained constant in both cell lines, suggesting that the same amount of protein was bound to chromatin (Figure S4D). We reasoned that this higher HP1 $\alpha$ recovery rate might arise from altered heterochromatin acting as a barrier to protein diffusion. Since the integrity of the heterochromatin boundary results in a high variance of HP1 $\alpha$ signal over time at the edge of a chromocenter (Strom et al., 2017), we quantified temporal changes in GFP-HP1a signal intensity variation at chromocenter borders (Figure 4D). As expected, we found that variance levels were low in the nucleoplasm of WT ESCs, and only increased at chromocenters, peaking at the borders of chromocenters. However, the variance from HP1 $\alpha$ in Daxx KO cells displayed a strikingly different pattern (Figure 4D). In both serum and ground-state conditions, the peak of signal variance at the edge of chromocenters was significantly lower in the absence of DAXX suggesting a compromised heterochromatin barrier (Figure 4D). At the molecular level, Daxx deletion in pluripotent ESCs increased the kinetics of MNase digestion of pericentric heterochromatin (Figure S4E). This enhanced chromatin accessibility confirmed that PCH exists in an abnormal state Daxx KO cells.

Overall, our data indicate that DAXX regulates $\mathrm{PCH}$ compaction state, chromocenter boundary properties and major satellite clustering. We conclude that DAXX is essential for PCH assembly and spatial organization in pluripotent ESCs. 


\section{DAXX recruits SETDB1 to chromocenters in ground-state ESCs.}

In ground-state ESCs, DAXX is recruited to major satellites upon DNA damage thereby facilitating $\mathrm{PCH}$ formation. To investigate the mechanism underlying DAXX function, we searched for factors interacting with DAXX and PML that could be recruited specifically to chromocenters. Amongst the described DAXX interacting partners SETDB1, an H3K9me3 methyltransferase, colocalizes with DAXX at PML nuclear bodies and is important for repetitive DNA transcriptional silencing (S. Cho et al., 2011; Karimi et al., 2011). SETDB1 partially colocalized with PML-NBs in a DAXX-independent manner in serum conditions (Figure S5A). Under $2 \mathrm{i}+\mathrm{VitC}$ treatment, SETDB1 relocalized to $\mathrm{PCH}$ with DAXX and PML in $70 \%$ of WT ESCs (Figure 5A). By contrast, SETDB1 was associated with chromocenters in $17 \%$ of Daxx $\mathrm{KO}$ cells, but remained associated with regular PML nuclear bodies, indicating that DAXX is critical for SETDB1 recruitment specifically to chromocenters (Figure 5A). Similarly, PML failed to be recruited at chromocenters in the absence of DAXX. To confirm that DAXX was sufficient

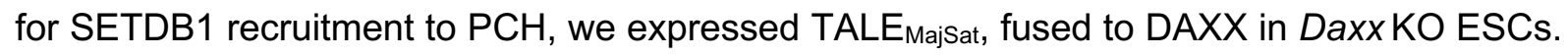
TALE-mediated DAXX binding to major satellite repeats drastically increased the amount of SETDB1 signal observed at chromocenters (Figure S5B).

DAXX deletion had no effect on H3K9me3 levels at chromocenters independently of culture conditions (Figure S5C). Since DAXX deletion prevented SETDB1 recruitment to $\mathrm{PCH}$, it suggests that the majority of $\mathrm{H} 3 \mathrm{~K} 9 \mathrm{me} 3$ deposition at chromocenters relies on SUV39H1/2 (Lehnertz et al., 2003; Peters et al., 2001). To test whether SETDB1 supports H3K9me3 deposition at $\mathrm{PCH}$ upon $2 \mathrm{i}+\mathrm{VitC}$ treatment, we took advantage of Suv39H1/2 double knockout (Suv39dKO) ESCs. In the absence of Suv39H1/2, H3K9me3 can only result from SETDB1 activity. Importantly, there was no growth defect in Suv39dKO cells in $2 i+V i t C$ medium showing that both enzymes are dispensable for the ground-state of pluripotency. As expected, Suv39dKO did not accumulate H3K9me3 at major satellite foci in contrast to WT ESCs (Figure 5B). Yet, upon ground-state conversion, some major satellite foci surrounded by PML showed 
a strong accumulation of $\mathrm{H} 3 \mathrm{~K} 9$ me3 suggesting that the fraction of SETDB1 recruited to $\mathrm{PCH}$ is indeed functionally active (Figure 5B).

Overall, our results demonstrate that SETDB1 is recruited by DAXX to $\mathrm{PCH}$ upon $2 \mathrm{i}+\mathrm{VitC}$ conversion where it can locally trimethylate H3K9.

\section{H3.3K9 modification is crucial for $\mathrm{PCH}$ organization}

The apparent contradiction between the DAXX-mediated SETDB1 recruitment and the unchanged amount of H3K9me3 observed in Daxx KO ESCs, prompted us to dissect the respective roles of DAXX, SETDB1 and $\mathrm{H} 3 \mathrm{~K} 9 \mathrm{me} 3$ in the spatial organization of chromocenters. We used the TALE MajSat $_{\text {to }}$ specifically target DAXX, SETDB1 or SUV39H1 to chromocenters in Suv39dKO ESCs (Figure 5C). Both histone methyltransferases were able to individually restore $\mathrm{H} 3 \mathrm{~K} 9 \mathrm{me} 3$ at chromocenters, when targeted by TALE $\mathrm{MajSat}_{\text {. The specific }}$ recruitment of DAXX to major satellite foci also promoted H3K9me3 deposition via SETDB1, at $70 \%$ of chromocenters (Figure 5D). We measured the impact of the different TALE $\mathrm{MajSat}$ fusions on chromocenter clustering by counting the number TALE-bound foci (Figure 5E). Consistent with our observations in Daxx KO and WT ESCs (Figure 4B, S4C), targeting DAXX to major satellite also enhanced chromocenter clustering in Suv39dKO ESCs as evidenced by the reduced number of PCH foci (Figure 5E). However, the recruitment of either SETDB1 or SUV39H1 did not affect the number of chromocenters, demonstrating that $\mathrm{H} 3 \mathrm{~K} 9 \mathrm{me} 3$ per se does not influence PCH clustering (Figure 5E).

Since DAXX, unlike SETDB1, had a direct impact on the spatial organization of chromocenters, we wondered whether its $\mathrm{H} 3.3$ chaperone activity is involved in $\mathrm{PCH}$ clustering. We expressed DAXX containing a point mutation of Tyr222, a residue required for DAXX interaction with $\mathrm{H} 3.3$ (Elsässer et al., 2012). As expected, the capacity of a TALE ${ }_{\text {Majsat }}$ DAXX ${ }^{Y 222 A}$ fusion to coimmunoprecipitate with $\mathrm{H} 3.3$ was drastically reduced compared to its wild-type counterpart (Figure S5D). While targeting DAXX to chromocenters could recruit a tagged version of H3.3, 
neither the control TALE nor its fusion with DAXX ${ }^{\mathrm{Y} 222 \mathrm{~A}}$ were able to mobilize $\mathrm{H} 3.3$ to $\mathrm{PCH}$ (Figure S5E). When expressed in Suv39dKO ESCs, the TALE fusion with DAXX ${ }^{\mathrm{Y} 222 \mathrm{~A}}$ did not increase H3K9me3 levels at chromocenters, as it failed to recruit SETDB1 (Figure 5C, S5B). Importantly, the Y222A mutant did not change the number of chromocenters arguing that $\mathrm{H} 3.3$ is crucial for DAXX-mediated PCH clustering (Figure 5D). To confirm a function for H3.3 in chromocenter organization, we depleted endogenous $\mathrm{H} 3.3$ using a pool of siRNAs targeting

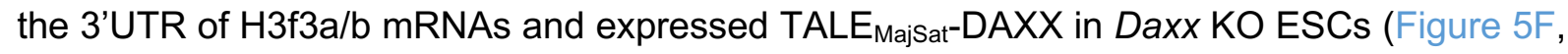
S5F). The H3.3 knock-down was rescued by the expression of different HA-tagged versions of H3.3, which were assessed for their impact on chromocenter clustering by immuno-FISH (Figure 5F, S5F). The binding of DAXX at major satellite did not enhance PCH clustering when H3.3 was knocked down. The expression of a wild-type H3.3-HA significantly reduced the number of major satellite foci and rescued the chromocenter hyperclustering phenotype mediated by TALE $\mathrm{MajSat}-\mathrm{DAXX}$. In contrast, expression of $\mathrm{H} 3.3^{\mathrm{G} 90 \mathrm{M}}$, a mutant unable to bind DAXX (Elsässer et al., 2012; Hoelper et al., 2017), did not decrease the number of major satellite foci (Figure 5F). This result is consistent with the absence of a chromocenter clustering phenotype in cells transfected by TALE $\mathrm{MajSat}_{-}$DAXX ${ }^{\mathrm{Y} 22 \mathrm{~A}}$ (Figure 5E) and confirms the important role of $\mathrm{H} 3.3$ in $\mathrm{PCH}$ clustering. Since DAXX can recruit SETDB1 to $\mathrm{PCH}$, we asked whether the post-translational modification $\mathrm{H} 3.3 \mathrm{~K} 9$ impacts $\mathrm{PCH}$ clustering. We used H3.3K9A, a mutant that cannot be methylated. Like $\mathrm{H} 3.3^{\mathrm{G} 90 \mathrm{M}}, \mathrm{H} 3.3^{\mathrm{K} 9 \mathrm{~A}}$ failed to rescue the hyper-clustering phenotype in TALE $\mathrm{Majsat}-\mathrm{DAXX}$ expressing cells, suggesting that the modification of this residue is essential for the spatial organization of chromocenters.

Altogether, we demonstrate that $\mathrm{H} 3.3 \mathrm{~K} 9$ modification is important for facilitating the spatial organization of $\mathrm{PCH}$ in pluripotent ESCs. 


\section{Discussion}

During early embryogenesis, adapting heterochromatin to compensate for the wave of DNA demethylation is essential to maintain transcriptional repression of repetitive DNA and protect genome integrity. The mechanisms and molecular factors responsible for heterochromatin reorganization were however, largely unknown. Here, we describe a novel and essential role for the H3.3-chaperone DAXX in PCH maintenance and the survival of ground-state pluripotent stem cells. Taken together, our results support a model in which DAXX facilitates pericentric heterochromatin formation after DNA damage in ground-state ESCs (Figure 6A). Upon groundstate conversion, active DNA demethylation provokes the accumulation DNA damage at major satellites. We show that DAXX is mobilized to major satellite regions in response to such damage to reform heterochromatin. DAXX deposits H3.3 and recruits SETDB1, which can methylate H3.3K9. In the absence of DAXX, PCH is compromised (Figure 6B). In Daxx KO ESCs, heterochromatin at major satellite is less compact and partially loses its boundary properties leading to defective chromocenter clustering. This failure to reform PCH after DNA damage could directly contribute to the loss of cell viability observed in Daxx KO ground-state ESCs.

\section{DAXX and H3.3 impact chromocenter organization}

Both DAXX and H3.3 are essential for early embryogenesis, but their exact functions were elusive (Jang et al., 2015; Lin et al., 2013; Liu et al., 2020; Michaelson et al., 1999). In ESCs, we found that DAXX limits expression of satellite RNA, which is consistent with its previously described repressive role at transposable elements in these cells (Elsässer et al., 2015; Hoelper et al., 2017). The derepression of major satellites in Daxx KO ESCs, correlates with defects in spatial organization of chromocenters and a loss of boundary properties of PCH (Figure 4A, 4C, 4D). This function of DAXX in $\mathrm{PCH}$ organization could explain why $\mathrm{H} 3 \mathrm{f} 3 \mathrm{a} / \mathrm{b}$ double knockout ESCs exhibit severe chromosome segregation defects (Jang et al., 2015). 
While Daxx deletion had no impact on major satellite transcription and chromocenter formation upon neurectoderm differentiation (Figure S1C, S1D, 4A), DAXX and H3.3 are important for chromocenter clustering during myoblast differentiation (Park et al., 2018; Salsman et al., 2017). In myoblasts, DAXX is recruited to chromocenters, where H3.3 deposition stimulates transcription of major satellites, suggesting a mechanism different to the one we observed in ESCs. Different DAXX recruitment pathways could explain the opposite impact of DAXX and H3.3 on major satellite transcription. In ESCs, DAXX is recruited after DNA damage alongside SETDB1, thus favoring a repressive chromatin environment. Upon myoblast differentiation, Setdb1 is downregulated and might not be available for interaction with DAXX, which is recruited to major satellite repeats by the muscle-specific IncRNA ChRO1 (Park et al., 2018; Song et al., 2015).

A recent understanding of chromocenter organization came from the observation that the intrinsically disordered regions of HP1 $\alpha$ facilitate the compartmentalization of chromocenters through liquid-liquid phase separation (Larson et al., 2017; Strom et al., 2017). Since the first fifty amino-acids and the C-terminal half of DAXX are intrinsically disordered (Escobar-Cabrera et al., 2010), it is possible that DAXX could also undergo liquid-liquid phase separation. Multivalent interactions between chromodomains recognizing H3K9me3 have also been proposed to contribute to phase separation of heterochromatin (Wang et al., 2019). Yet, z deletion impacted the boundary properties of pericentromeric heterochromatin without affecting H3K9me3 (Figure 4D, S5C). Since DAXX-mediated chromocenter clustering relies on H3.3K9 modification (Figure 5F), future work will compare the interaction of HP1 $1 \alpha$ and additional heterochromatin-related proteins to H3.3K9me3 vs. H3K9me3.

\section{DAXX is targeted to damaged heterochromatin}

During early embryogenesis, PCH reorganization into chromocenters coincides with high levels of DNA damage signaling (Ziegler-Birling et al., 2009). Here, we provide evidence that DAXX recruitment to pericentromeric heterochromatin in ground-state ESCs, in response to DNA damage, facilitates chromocenter formation. Therefore, we propose the hypothesis that 
chromatin remodeling after DNA damage contributes to heterochromatin transition occurring during the first steps of embryogenesis.

Several studies have described H3.3 incorporation after DNA damage (Adam et al., 2013; Juhász et al., 2018; Li and Tyler, 2016; Luijsterburg et al., 2016). Both HIRA and DAXX-ATRX complexes have been proposed to deposit H3.3 after DNA damage. HIRA recruitment was shown to be required to restart transcription after UV damage suggesting that HIRA is the main pathway for H3.3 deposition at damaged euchromatin (Adam et al., 2013). Since our results indicate that DAXX is recruited to constitutive heterochromatin, we propose that the chromatin environment could directly dictate the choice of H3.3 deposition pathway. However, the role of H3.3 deposition after DNA damage remains debated. While several studies support a direct role for H3.3 during the repair process (Adam et al., 2013; Juhász et al., 2018; Luijsterburg et al., 2016), it has also been proposed that $\mathrm{H} 3.3$ contributes to chromatin reassembly after repair (Li and Tyler, 2016). Since DAXX recruitment to chromocenters does not always co-localize with $\mathrm{YH} 2 \mathrm{AX}$, DAXX probably binds to DNA damage sites after DNA repair and could facilitate $\mathrm{PCH}$ reformation. Indeed, local epigenetic information within $\mathrm{PCH}$ is erased after the detection of DNA damage by nucleosome eviction and H3K9 histone demethylase recruitment (Janssen et al., 2019; Khoury-Haddad et al., 2014; Li and Tyler, 2016; Young et al., 2013). By recruiting SETDB1, DAXX could facilitate the reestablishment of H3K9me3 after DNA repair, directly contributing to the epigenetic inheritance of pericentromeric heterochromatin.

\section{Role of SETDB1 at chromocenters in ground-state ESCs}

SETDB1 has been shown to be responsible for $\mathrm{H} 3 \mathrm{~K} 9 \mathrm{me} 3$ deposition at transposable elements and telomeres (Elsässer et al., 2015; Gauchier et al., 2019; Karimi et al., 2011). Yet, knocking down SETB1 in Suv39h1/h2 double knock-out cells destabilizes chromocenters suggesting that SETDB1 could be involved in PCH formation (Pinheiro et al., 2012). Our data show that DAXX recruits SETDB1 to pericentromeric heterochromatin after DNA damage. In contrast to SUV39H1/H2, SETDB1 contains a triple Tudor domain recognizing the double modification K14 acetylation and K9 methylation that may facilitate its binding to hyperacetylated, newly 
incorporated histone H3 (Jurkowska et al., 2017). Using ESCs lacking Suv39h1/h2, we found that SETDB1 can deposit H3K9me3 at chromocenters (Figure 5B). This function of SETDB1 is consistent with its role at transposable element in ESCs (Elsässer et al., 2015). Yet, it contrasts with the observation that SETDB1 promotes H3K9me1 at major satellites in mouse embryonic fibroblasts (Loyola et al., 2009). However, SETDB1 was specifically recruited during S-phase by the H3.1/H3.2 chaperone, CAF1, suggesting that SETDB1 substrate specificity might change depending on its recruitment pathway. Similar to our data in ESCs, CAF1 recruited SETDB1 to chromocenters only in a subset of S-phase cells. Since pericentromeric satellites were shown to be particularly sensitive to replicative stress, SETDB1 recruitment could also result from DNA damage (Crosetto et al., 2013).

\section{The role of DAXX and H3.3 upon DNA hypomethylation}

This study reveals that DAXX is recruited to pericentromeres in the context of DNA hypomethylation. While PML nuclear bodies are generally devoid of chromatin, we observed the formation of atypical nuclear bodies containing DAXX-bound major satellites surrounded by a shell of PML in hypomethylated ESCs (Figure 2A, 3A). Similar nuclear bodies have been observed in patients with immunodeficiency, centromeric instability and facial dysmorphia (ICF) syndrome associated with mutations in a DNA methyltransferase (Luciani et al., 2006). In patient lymphocytes, DAXX and DNA repair proteins accumulate at hypomethylated pericentromeric satellites, suggesting that our proposed model could apply to other pathological conditions (Figure 6). Our results suggests that active DNA demethylation causes DNA damage leading to DAXX recruitment. In the absence of DNA methyltransferase, neither DAXX nor SETDB1 were found associated with unmethylated major satellite supporting a crucial role for active demethylation (Saksouk et al., 2014). Connection between active demethylation and DAXX-SETDB1 recruitment is also supported by previous reports on early embryogenesis. In the zygote, DAXX and SETDB1 accumulate at perinucleolar rims where major satellites are nested (Arakawa et al., 2015; S. Cho et al., 2012; Liu et al., 2020). They are mainly recruited in the male pronucleus, which is also more subject to active demethylation 
and DNA damage (lqbal et al., 2011; Nakatani et al., 2015; Wossidlo et al., 2011). While it remains unknown whether DAXX is necessary for chromocenter formation in vivo, the viability of Daxx KO embryos drops following the 4-cell stage when chromocenters should form, supporting our conclusion that the role of DAXX at $\mathrm{PCH}$ might be crucial for the ground-state of pluripotency (Liu et al., 2020).

In conclusion, our study reveals how DAXX and H3.3 facilitate chromocenter formation and protect epigenome integrity in ground-state ESCs. It would be interesting to characterize whether DAXX also contributes to the 3D-organization of other heterochromatin domains, such as the clustering of LINE1 elements (Lu et al., 2021). Beyond early development, our work could also provide insight into the molecular pathways that overcome DNA hypomethylation transitions in pathological contexts, including diverse cancers.

\section{Material and Methods}

\section{Cell lines}

Feeder-free E14 mES cells were used for most experiment excepts otherwise notified. E14 mES cells were kindly provided by Pablo Navaro (Pasteur Institute). Daxx KO cell line was constructed using CRISPR/cas9 editing in E14 mES cells. Guide-RNA was designed using the online CRISPOR tool. Oligos were designed with a Bbsl site on 5' to clone them into the pSpCas9(BB)-2A-Puro(pX459) v2.0 vector (Ran et al., 2013). Guide was designed carrying two guanines on 5' of the sequence to avoid off-target effects, as previously described (S. W. Cho et al., 2014). Sg-mDaxx: gGACCTCATCCAGCCGGTTCA. Feeder-free Suv39HdKO and corresponding WT R1 ES cells were provided by Alice Jouneau and generated in Antoine Peters's laboratory (Lehnertz et al., 2003). 


\section{Culture conditions}

Pluripotent cells were cultured either in a serum condition, defined as follow: DMEM (Gibco), supplemented with $10 \%$ of ESC-certified FBS (Gibco), 2-mercaptoethanol (0.05mM, Gibco), Glutamax (Gibco), MEM non-essential amino acids (0.1mM, Gibco), Penn-Strep (100units/mL, Gibco) and LIF (1000units/mL,) for serum condition. Serum-cultivated cells were grown on $0.1 \%$ gelatin-coated plates or stem cell plates (Stem Cell technology) at $37^{\circ} \mathrm{C}$ with $5 \% \mathrm{CO} 2$. Medium was changed every day and cells were passaged every 2 to 3 days. The other culture condition is the chemically defined serum-free $2 \mathrm{i}$ condition defined as follow: Neurobasal:DMEM/F-12 (50:50, Gibco) medium, supplemented with N2 and B-27 supplements (Gibco), BSA fraction $\vee\left(0.05 \%\right.$ Gibco), 1-thioglycerol $\left(1.5 \times 10^{-4} \mathrm{M}\right.$, Sigma) and ESGRO 2 inhibitors (GSK3i and MEKi) and LIF (Merck). Vitamin C (L-ascorbic acid 2phosphate, Sigma) was added at a concentration of $100 \mu \mathrm{g} / \mathrm{mL}$ (Blaschke et al., 2013). Cells were grown on $0.1 \%$ gelatin-coated plates. Medium was changed daily. Cells were passed every 2 days at $1: 4$ ratio for the first passage then at a 1:6 ratio. Additional media used were constituted as follow: serum medium supplemented with either 5 -azacytidine $(2 \mu \mathrm{M}$, Sigma) or Hydroxy-Urea (2mM, Sigma). Differentiation of mES cells was done by LIF removal for the first 24h. Then, non-LIF medium was supplemented with retinoic acid $\left(10^{-6} \mathrm{M}\right.$, ) for 4 days. For cell growth quantification, cells were counted at each passage for at least 2 different experiments.

\section{Vectors and transfections}

Cells were harvested using trypsin and one million was plated in a $0.1 \%$ gelatin-coated plate and transected with 0.2 to $2.5 \mu \mathrm{g}$ of DNA using the Lipofectamine 2000 reagent (Thermo), following manufacturer's protocol. TALE vectors were constructed using previously described methods (Ding et al., 2013). A TALE specific DNA binding domain targeting Major Satellite repeats was created by the modular assembly of individual TALE repeats inserted into a backbone vector containing TALE-Nrp1-VP64 previously described (Therizols et al., 2014). The BamHI-Nhel fragment containing VP64 was replaced by PCR products encoding the DAXX protein, corresponding DAXX mutants or additional proteins such as SUV39H1 and 
TET1CD. CDS of the different proteins were amplified by PCR from cDNAs obtained after RNA extraction of serum E14 mES cells. DAXX mutants were generated by PCR from WT DAXX.

Oligos for major satellites targeting were designed with a Bbsl site on 5' to clone them into the pSpCas9(BB)-2A-Puro(pX459) v2.0 vector (Ran et al., 2013). Catalytically dead Cas9 (dCas9) was inserted into the pSpCas9-2A-Puro(pX459) v2.0 to generate a SpdCas9-2A-Puro.

Target sequences for the TALE repeat domains and dCas9 associated guides RNA are listed in supplementary table.

\section{RNA extraction for RNAseq or RT-qPCR}

Total RNA was extracted using RNeasy extraction kit (Qiagen) according with manufacturer's protocol including DNAsel treatment for $15 \mathrm{~min}$ at room temperature (Qiagen). Complementary DNA were generated from $1 \mu \mathrm{g}$ of RNA using the Maxima first strand cDNA synthesis kit (Thermo Fisher), with a second round of DNAsel from the Maxima kit for 15min. Real-time qPCR was carried out using a LightCycler 480 instrument (Roche) and the LightCycler 480 SYBR green master mix (Roche). The qRT-PCR primers used in this study are listed in supplementary table. Three independent biological repeats were obtained for each sample. For RNAseq experiment, RNA quality was assessed using the Agilent 2100 bioanalyzer. Libraries were prepared using oligo(dT) beads for mRNA enrichment, then fragmented and reverse transcribed using random hexamers primer. After adaptor ligation, the double-stranded cDNA is completed through size selection of $250-300 \mathrm{bp}$ and PCR amplification, then quality of the library is assessed by the Agilent 2100 bioanalyzer. Sequencing was performed in 150bp paired-end reads using an Illumina sequencer platform.

\section{RNA-seq Mapping and Processing}

FASTQ files generated by paired end sequencing were aligned to the mouse genome using bowtie2 v2.2.6 (parameters: --local --threads 3; mm9 genome build). Mapped RNA-seq data was processed using tools from the HOMER suite (v4.8). SAM files were converted into tag directories using 'makeTagDirectory' (parameters: -format sam -sspe). Genomic intervals 
which extended beyond the end of the chromosomes was removed using 'removeOutOfBoundsReads.pl'. bigWig browser track files were generated using 'makeUCSCfile' (parameters: -fsize 1e20 -strand + -norm 1e8). For gene expression analysis, read depths were quantified for all annotated refseq genes using analyzeRepeats.pl (parameters: rna mm9 -strand both -count exons -rpkm -normMatrix 1e7 -condenseGenes). For repeat analysis, read coverage was quantified for each repeat and then condensed to a single value for each named entry (parameters: repeats mm9 -strand both -rpkm -normMatrix 1 e7 -condenseL1). Read depths were then corrected for the number of instances of each repeat prior to expression analysis.

\section{Expression Analysis}

Quantified RNA-seq data was processed using the limma package (R/Bioconductor)(Team, 2017). Following the addition of an offset value (1 RPKM) to each gene or repeat, data was normalised across all samples using 'normalizeBetweenArrays' with method='quantile'. Foldchanges and $p$-values for differential expression of genes and repeats were determined using empirical Bayes statistics. Briefly, data was fit to a linear model using 'ImFit' and specified contrasts were applied using 'makeContrasts' and 'contrasts.fit'. Data was processed using the 'topTable' function with adjust.method="BH" (Benjamini-Hochberg multiple-testing correction). Differential expression was defined as log2 fold change $\leq-1$ or $\geq 1$ and an adjusted $p$-value of $\leq 0.01$. Three biological replicates for each condition represent independently cultured pools of cells.

\section{Data visualization}

Heatmaps and boxplots were generated using Prism GraphPad (v8). Histograms were drawn using either Prism GraphPad or Excel. Volcano plots were generated using the plot function in R. 


\section{Immunofluorescence}

Murine ES cells were harvested with trypsin (Gibco) and plated for $4-6 \mathrm{~h}$ onto $0.1 \%$ gelatincoated glass cover slips. Cells were fixed with $4 \%$ paraformaldehyde for $10 \mathrm{~min}$ at room temperature, then rinsed three times with PBS. Cells were permeabilized with $0.1 \mathrm{X}$ triton for $12 \mathrm{~min}$ at room temperature, then rinsed three times with PBS. Blocking was done in $3 \% \mathrm{BSA}$ solution for $30 \mathrm{~min}$ at room temperature. All incubations with primary antibodies were performed for either $1 \mathrm{~h}$ at room temperature or overnight at $4^{\circ} \mathrm{C}$ with the following antibodies for $\mathrm{H} 3 \mathrm{~K} 9 \mathrm{me} 3$ (Active Motif, 1:1000), DAXX (Santa Cruz, 1:500), yH2AX (Abcam, 1:1000), PML () and SETDB1 (Proteintech, 1:100). Incubation with secondary antibodies (fluorescently labeled antimouse or anti-rabbit, 1:1000) were performed for $1 \mathrm{~h}$ at room temperature. Mounting was performed using ProLong Diamond with DAPI mounting media (Thermo). Antibodies are listed in supplementary table.

For $5 \mathrm{mC}$ staining, cells were fixed with $4 \%$ PFA for $10 \mathrm{~min}$ at room temperature, then permeabilized using $1 \% \mathrm{BSA}, 0.5 \%$ triton $\mathrm{X}-100$ for $30 \mathrm{~min}$ at room temperature. Cells were washed 3 times in PBS before incubation with RNAse A $(20 \mathrm{mg} / \mathrm{mL})$ for $1 \mathrm{~h}$ at $37^{\circ} \mathrm{C}$. Cells washed 3 times in PBS, then denatured in $4 \mathrm{M} \mathrm{HCl}$ for 10 min at $37^{\circ} \mathrm{C}$. Slides are neutralized by extensive washes in PBS, then blocked in $1 \%$ BSA, $0.1 \%$ Triton $\mathrm{X}-100$ for 30 min at room temperature before incubation with $5 \mathrm{mC}$ antibody (Diagenode, $1: 1000$ ) overnight at $4^{\circ} \mathrm{C}$. After 3 washes in PBS, cells were blocked in 1\% BSA, $0.1 \%$ Triton X-100 for 30 min at room temperature before incubation with secondary antibody for $1 \mathrm{~h}$ at room temperature. Mounting was performed using ProLong Diamond with DAPI mounting media (Thermo).

\section{Fluorescent in situ Hybridization}

Murine ES cells were harvested with trypsin (Gibco) and plated for $4-6 \mathrm{~h}$ onto $0.1 \%$ gelatincoated glass cover slips. Cells were fixed with $4 \%$ paraformaldehyde (PFA) for $10 \mathrm{~min}$ at room temperature, then rinsed three times with PBS. Cells were permeabilized with $0.5 \mathrm{X}$ triton for $12 \mathrm{~min}$ at room temperature, then rinsed three times with PBS. Cells were briefly washed in $2 X$ 
SSC, then treated with RNAseA $\left(100 \mu \mathrm{g} / \mathrm{mL}\right.$, Sigma) for $1 \mathrm{~h}$ at $37^{\circ} \mathrm{C}$. Cells were briefly washed in 2 XSC, then denatured by serial 2 min incubation into 70,90 and $100 \%$ ethanol. Cover slips were air dried for $15 \mathrm{~min}$. Cover slips are incubated with $200 \mathrm{nM}$ of PNA probe, placed for $10 \mathrm{~min}$ at $95^{\circ} \mathrm{C}$ for denaturation, then placed for $1 \mathrm{~h}$ at room temperature in the dark for hybridization. Cover slips were washed twice in 2 XSC $0.1 \%$ Tween- 20 for $10 \mathrm{~min}$ at $60^{\circ} \mathrm{C}$. Cover slips were immerged at room temperature in 2 X SSC $0.1 \%$ Tween-20 for $2 \mathrm{~min}$, then in $2 \mathrm{X} \mathrm{SSC}$ for $2 \mathrm{~min}$ and 1X SSC for $2 \mathrm{~min}$. Mounting is performed using ProLong Diamond with DAPI mounting media (Thermo).

\section{Dot blot experiments}

DNA extraction was performed using the Wizard genomic DNA extraction kit (Promega). Genomic DNA $(1 \mu \mathrm{g})$ was then denatured in $0.1 \mathrm{M} \mathrm{NaOH}$ for $10 \mathrm{~min}$ at $95^{\circ} \mathrm{C}$ before neutralization with $1 \mathrm{M} \mathrm{NH} 4 \mathrm{OAc}$ on ice for $5 \mathrm{~min}$. DNA samples were spotted on a nitrocellulose membrane. Blotted membrane was washed in $2 \mathrm{X} \mathrm{SSC}$ and dried at $80^{\circ} \mathrm{C}$ for $5 \mathrm{~min}$ before $\mathrm{UV}$ cross-linking at $120,000 \mu \mathrm{J} / \mathrm{cm} 2$. Membrane was then blocked using PBS, $5 \%$ milk $0.1 \%$ tween for $30 \mathrm{~min}$ at room temperature. Membrane was incubated with $5 \mathrm{mC}$ antibody (Diagenode, 1:1000) for $3 \mathrm{~h}$ at room temperature. After 3 washes of 10min each in PBS, membrane was blocked again for $30 \mathrm{~min}$ and then incubated with secondary anti-HRP antibody for $1 \mathrm{~h}$ at room temperature. Membrane was washed 3 times for $10 \mathrm{~min}$ in PBS and visualized by chemiluminescence with ECL Plus.

\section{Fluorescent Recovery After Photobleaching and variance analysis}

Murine ES cells transfected with HP1a-GFP were harvested with trypsin (Gibco) and plated for $4-6 \mathrm{~h}$ onto $0.1 \%$ gelatin-coated glass live-cell Nunc slides (Thermo). FRAP experiment was carried with an LSM 800 confocal microscope (Zeiss). The $488 \mathrm{~nm}$ laser was used to bleach and acquire GFP signal. 1 image was taken before a bleach pulse of $5 \mathrm{~ms}$. Bleaching area was set to target a single pericentric domain. Images were acquired every second during 35 s post- 
bleach. FRAP analysis was performed using a FRAP analysis ImageJ Jython script, that generated FRAP curves and the associated half-recovery time and mobile fraction parameters. GFP-HP1 $\alpha$ variance along time was obtained from ImageJ analysis using standard deviation z-projection along time for the whole duration of the movie. Quantification of heterochromatin barriers were performed using a $1 \mu \mathrm{m}$ line across individual non-bleached chromocenter borders, for which the variance intensity along time was measured with the ImageJ software.

\section{Image acquisition and analysis}

Images for immunofluorescence and FISH experiments were obtained with an inverted Nikon Ti Eclipse widefield microscope using a 60X immersion objective and LED sources. Z-stacks images were taken and then deconvoluted using a custom ImageJ deconvolution script. Quantifications of images were performed using custom lcy scripts. Number of major satellite foci were counted using a custom Icy script and performed onto the medium focal plane.

DNA methylation at chromocenters from the Tale-TET1CD experiments were measured using a $2 \mu \mathrm{m}$ line across individual DAPI-dense chromocenters. Intensity profiles were obtained and the mean with SEM were calculated for DAPI and $5 \mathrm{mC}$ signals for each condition. Two to three chromocenters per nucleus were analyzed.

H3K9me3 intensities at chromocenters were measured using à $2 \mu \mathrm{m}$ line across individual DAPI-dense chromocenters. Two to three chromocenters per nucleus were analyzed.

DNA damage signaling, SETDB1 and H3K9me3-recruitments at chromocenters were counted manually.

\section{Statistical analysis}

Number of objects counted, and statistical tests performed are indicated in the text, figure or figure legends. All statistical analysis results are listed in supplementary file. Pvalues are represented as follow: ${ }^{*}<0.05 ;^{* *}<0.01 ;{ }^{* * *}<0.001 ;{ }^{* * *}<0.0001$. 


\section{Western Blotting}

Total protein extracts were prepared in RIPA buffer with protease inhibitor cocktail (Roche). Samples were sonicated for 3 minutes alterning 30seconds ON/ 30seconds OFF. Proteins were separated by electrophoresis in $8-15 \%$ poly-acrylamide gels then transferred onto nitrocellulose membranes. Membranes were incubated in ponceau then washed in PBS, $0.1 \%$ tween. Membranes were blocked in PBS, $0.1 \%$ tween, $5 \%$ milk for $30 \mathrm{~min}$ at room temperature before incubation with primary antibody overnight at $4^{\circ} \mathrm{C}$. After 3 washed in PBS, $0.1 \%$ tween, membranes were incubated with secondary HRP-conjugated antibody for $1 \mathrm{~h}$ at room temperature. Membranes were washed 3 times in PBS, $0.1 \%$ tween and visualized by chemoluminescence using ECL Plus.

\section{Acknowledgements}

This work was funded by Agence Nationale pour la Recherche (ANR-16-CE12-0003) and La Ligue Nationale Contre le Cancer (LNCC)-Comité lle de France. AC was supported by MESR and LNCC. We would like to thank A. Bonnet-Garnier and A. Jouneau for the gift of Suv39dKO KO ESCs and advice. We are also grateful to image core microscopy facilities of IRSL, Paris, in particular N. Setterblad for his assistance with live imaging. We warmly thank V. Lallemand-Breitenbach and $\mathrm{H}$. de Thé (Collège de France, Paris, France) for the sharing of PML antibody and helpful advice. We kindly thank $\mathrm{P}$. Lesage for her critical readings of the manuscript, and other members of the team for helpful advice. We finally thank support services of IRSL. The authors declare no conflict of interest. 


\section{Author Contributions}

AC, AV, PT, performed all experiments, RI analyzed RNAseq data. AC, AV, PT designed experiments, interpreted data. AC, EF, PT contributed to the writing of the manuscript. All authors reviewed the manuscript.

\section{Declaration of interest}

The authors declare no competing interests.

\section{References}

Adam, S., Polo, S.E., Almouzni, G., 2013. Transcription recovery after DNA damage requires chromatin priming by the H3.3 histone chaperone HIRA. Cell 155, 94-106. doi:10.1016/j.cell.2013.08.029

Aloia, L., Di Stefano, B., Di Croce, L., 2013. Polycomb complexes in stem cells and embryonic development. Development 140, 2525-2534. doi:10.1242/dev.091553

Arakawa, T., Nakatani, T., Oda, M., Kimura, Y., Sekita, Y., Kimura, T., Nakamura, T., Nakano, T., 2015. Stella controls chromocenter formation through regulation of Daxx expression in 2-cell embryos. Biochem. Biophys. Res. Commun. 466, 60-65. doi:10.1016/j.bbrc.2015.08.106

Blaschke, K., Ebata, K.T., Karimi, M.M., Zepeda-Martínez, J.A., Goyal, P., Mahapatra, S., Tam, A., Laird, D.J., Hirst, M., Rao, A., Lorincz, M.C., Ramalho-Santos, M., 2013. Vitamin $C$ induces Tet-dependent DNA demethylation and a blastocyst-like state in ES cells. Nature 500, 222-226. doi:10.1038/nature12362

Borgel, J., Guibert, S., Li, Y., Chiba, H., Schübeler, D., Sasaki, H., Forné, T., Weber, M., 2010. Targets and dynamics of promoter DNA methylation during early mouse development. Nat. Genet. 42, 1093-1100. doi:10.1038/ng.708

Casanova, M., Pasternak, M., Marjou, El, F., Le Baccon, P., Probst, A.V., Almouzni, G., 2013. Heterochromatin reorganization during early mouse development requires a singlestranded noncoding transcript. Cell Rep 4, 1156-1167. doi:10.1016/j.celrep.2013.08.015

Cho, S., Park, J.S., Kang, Y.-K., 2011. Dual functions of histone-lysine N-methyltransferase Setdb1 protein at promyelocytic leukemia-nuclear body (PML-NB): maintaining PML-NB structure and regulating the expression of its associated genes. Journal of Biological Chemistry 286, 41115-41124. doi:10.1074/jbc.M111.248534

Cho, S., Park, J.S., Kwon, S., Kang, Y.-K., 2012. Dynamics of Setdb1 expression in early mouse development. Gene Expr Patterns 12, 213-218. doi:10.1016/j.gep.2012.03.005

Cho, S.W., Kim, S., Kim, Y., Kweon, J., Kim, H.S., Bae, S., Kim, J.-S., 2014. Analysis of offtarget effects of CRISPR/Cas-derived RNA-guided endonucleases and nickases. Genome Research 24, 132-141. doi:10.1101/gr.162339.113

Corless, S., Höcker, S., Erhardt, S., 2020. Centromeric RNA and Its Function at and Beyond Centromeric Chromatin. Journal of Molecular Biology 432, 4257-4269. doi:10.1016/j.jmb.2020.03.027

Crosetto, N., Mitra, A., Silva, M.J., Bienko, M., Dojer, N., Wang, Q., Karaca, E., Chiarle, R., Skrzypczak, M., Ginalski, K., Pasero, P., Rowicka, M., Dikic, I., 2013. Nucleotide-resolution 
DNA double-strand break mapping by next-generation sequencing. Nat. Methods $10,361-$ 365. doi:10.1038/nmeth.2408

Ding, Q., Lee, Y.-K., Schaefer, E.A.K., Peters, D.T., Veres, A., Kim, K., Kuperwasser, N., Motola, D.L., Meissner, T.B., Hendriks, W.T., Trevisan, M., Gupta, R.M., Moisan, A., Banks, E., Friesen, M., Schinzel, R.T., Xia, F., Tang, A., Xia, Y., Figueroa, E., Wann, A., Ahfeldt, T., Daheron, L., Zhang, F., Rubin, L.L., Peng, L.F., Chung, R.T., Musunuru, K., Cowan, C.A., 2013. A TALEN genome-editing system for generating human stem cellbased disease models. 12, 238-251. doi:10.1016/j.stem.2012.11.011

Elsässer, S.J., Huang, H., Lewis, P.W., Chin, J.W., Allis, C.D., Patel, D.J., 2012. DAXX envelops a histone H3.3-H4 dimer for H3.3-specific recognition. Nature 491, 560-565. doi:10.1038/nature11608

Elsässer, S.J., Noh, K.-M., Diaz, N., Allis, C.D., Banaszynski, L.A., 2015. Histone H3.3 is required for endogenous retroviral element silencing in embryonic stem cells. Nature 522, 240-244. doi:10.1038/nature14345

Escobar-Cabrera, E., Lau, D.K.W., Giovinazzi, S., Ishov, A.M., McIntosh, L.P., 2010. Structural characterization of the DAXX N-terminal helical bundle domain and its complex with Rassf1C. Structure 18, 1642-1653. doi:10.1016/j.str.2010.09.016

Falk, M., Feodorova, Y., Naumova, N., Imakaev, M., Lajoie, B.R., Leonhardt, H., Joffe, B., Dekker, J., Fudenberg, G., Solovei, I., Mirny, L.A., 2019. Heterochromatin drives compartmentalization of inverted and conventional nuclei. Nature 40, 47. doi:10.1038/s41586-019-1275-3

Fukuda, K., Okuda, A., Yusa, K., Shinkai, Y., 2018. A CRISPR knockout screen identifies SETDB1-target retroelement silencing factors in embryonic stem cells. Genome Research 28, 846-858. doi:10.1101/gr.227280.117

Gauchier, M., Kan, S., Barral, A., Sauzet, S., Agirre, E., Bonnell, E., Saksouk, N., Barth, T.K., Ide, S., Urbach, S., Wellinger, R.J., Luco, R.F., Imhof, A., Déjardin, J., 2019. SETDB1dependent heterochromatin stimulates alternative lengthening of telomeres. Sci Adv 5, eaav3673. doi:10.1126/sciadv.aav3673

Guenatri, M., Bailly, D., Maison, C., Almouzni, G., 2004. Mouse centric and pericentric satellite repeats form distinct functional heterochromatin. J. Cell Biol. 166, 493-505. doi:10.1083/jcb.200403109

Hahn, M., Dambacher, S., Dulev, S., Kuznetsova, A.Y., Eck, S., Wörz, S., Sadic, D., Schulte, M., Mallm, J.-P., Maiser, A., Debs, P., Melchner, von, H., Leonhardt, H., Schermelleh, L., Rohr, K., Rippe, K., Storchova, Z., Schotta, G., 2013. Suv4-20h2 mediates chromatin compaction and is important for cohesin recruitment to heterochromatin. Genes \& Development 27, 859-872. doi:10.1101/gad.210377.112

He, Q., Kim, H., Huang, R., Lu, W., Tang, M., Shi, F., Yang, D., Zhang, X., Huang, J., Liu, D., Songyang, Z., 2015. The Daxx/Atrx Complex Protects Tandem Repetitive Elements during DNA Hypomethylation by Promoting H3K9 Trimethylation. Cell Stem Cell 17, 273-286. doi:10.1016/j.stem.2015.07.022

Healton, S.E., Pinto, H.D., Mishra, L.N., Hamilton, G.A., Wheat, J.C., Swist-Rosowska, K., Shukeir, N., Dou, Y., Steidl, U., Jenuwein, T., Gamble, M.J., Skoultchi, A.I., 2020. H1 linker histones silence repetitive elements by promoting both histone H3K9 methylation and chromatin compaction. Proc. Natl. Acad. Sci. U.S.A. 117, 14251-14258. doi:10.1073/pnas.1920725117

Hinde, E., Cardarelli, F., Gratton, E., 2015. Spatiotemporal regulation of Heterochromatin Protein 1-alpha oligomerization and dynamics in live cells. Sci Rep 5, 12001-11. doi:10.1038/srep12001

Hoelper, D., Huang, H., Jain, A.Y., Patel, D.J., Lewis, P.W., 2017. Structural and mechanistic insights into ATRX-dependent and -independent functions of the histone chaperone DAXX. Nat Commun 8, 1193. doi:10.1038/s41467-017-01206-y

Iqbal, K., Jin, S.-G., Pfeifer, G.P., Szabó, P.E., 2011. Reprogramming of the paternal genome upon fertilization involves genome-wide oxidation of 5-methylcytosine. Proc. Natl. Acad. Sci. U.S.A. 108, 3642-3647. doi:10.1073/pnas.1014033108 
Jachowicz, J.W., Bing, X., Pontabry, J., Bošković, A., Rando, O.J., Torres-Padilla, M.-E., 2017. LINE-1 activation after fertilization regulates global chromatin accessibility in the early mouse embryo. Nat. Genet. 11, 778. doi:10.1038/ng.3945

Jagannathan, M., Cummings, R., Yamashita, Y.M., 2018. A conserved function for pericentromeric satellite DNA. Elife 7, 1218. doi:10.7554/eLife.34122

Jang, C.-W., Shibata, Y., Starmer, J., Yee, D., Magnuson, T., 2015. Histone H3.3 maintains genome integrity during mammalian development. Genes \& Development 29, 1377-1392. doi:10.1101/gad.264150.115

Janssen, A., Colmenares, S.U., Lee, T., Karpen, G.H., 2019. Timely double-strand break repair and pathway choice in pericentromeric heterochromatin depend on the histone demethylase dKDM4A. Genes \& Development 33, 103-115. doi:10.1101/gad.317537.118

Juhász, S., Elbakry, A., Mathes, A., Löbrich, M., 2018. ATRX Promotes DNA Repair Synthesis and Sister Chromatid Exchange during Homologous Recombination. Molecular Cell 71, 11-24.e7. doi:10.1016/j.molcel.2018.05.014

Jurkowska, R.Z., Qin, S., Kungulovski, G., Tempel, W., Liu, Y., Bashtrykov, P., Stiefelmaier, J., Jurkowski, T.P., Kudithipudi, S., Weirich, S., Tamas, R., Wu, H., Dombrovski, L., Loppnau, P., Reinhardt, R., Min, J., Jeltsch, A., 2017. H3K14ac is linked to methylation of H3K9 by the triple Tudor domain of SETDB1. Nat Commun 8, 2057. doi:10.1038/s41467017-02259-9

Karimi, M.M., Goyal, P., Maksakova, I.A., Bilenky, M., Leung, D., Tang, J.X., Shinkai, Y., Mager, D.L., Jones, S., Hirst, M., Lorincz, M.C., 2011. DNA methylation and SETDB1/H3K9me3 regulate predominantly distinct sets of genes, retroelements, and chimeric transcripts in mESCs. 8, 676-687. doi:10.1016/j.stem.2011.04.004

Khoury-Haddad, H., Guttmann-Raviv, N., Ipenberg, I., Huggins, D., Jeyasekharan, A.D., Ayoub, N., 2014. PARP1-dependent recruitment of KDM4D histone demethylase to DNA damage sites promotes double-strand break repair. Proc. Natl. Acad. Sci. U.S.A. 111, E728-37. doi:10.1073/pnas.1317585111

Lallemand-Breitenbach, V., de Thé, H., 2018. PML nuclear bodies: from architecture to function. Current Opinion in Cell Biology 52, 154-161. doi:10.1016/j.ceb.2018.03.011

Larson, A.G., Elnatan, D., Keenen, M.M., Trnka, M.J., Johnston, J.B., Burlingame, A.L., Agard, D.A., Redding, S., Narlikar, G.J., 2017. Liquid droplet formation by HP1a suggests a role for phase separation in heterochromatin. Nature 547, 236-240. doi:10.1038/nature22822

Lehnertz, B., Ueda, Y., Derijck, A.A.H.A., Braunschweig, U., Perez-Burgos, L., Kubicek, S., Chen, T., Li, E., Jenuwein, T., Peters, A.H.F.M., 2003. Suv39h-mediated histone H3 lysine 9 methylation directs DNA methylation to major satellite repeats at pericentric heterochromatin. Current Biology 13, 1192-1200. doi:10.1016/s0960-9822(03)00432-9

Leitch, H.G., McEwen, K.R., Turp, A., Encheva, V., Carroll, T., Grabole, N., Mansfield, W., Nashun, B., Knezovich, J.G., Smith, A., Surani, M.A., Hajkova, P., 2013. Naive pluripotency is associated with global DNA hypomethylation. Nat. Struct. Mol. Biol. 20, 19. doi:10.1038/nsmb. 2510

Lewis, P.W., Elsaesser, S.J., Noh, K.-M., Stadler, S.C., Allis, C.D., 2010. Daxx is an H3.3specific histone chaperone and cooperates with ATRX in replication-independent chromatin assembly at telomeres. Proc. Natl. Acad. Sci. U.S.A. 107, 14075-14080. doi:10.1073/pnas.1008850107

Li, X., Tyler, J.K., 2016. Nucleosome disassembly during human non-homologous end joining followed by concerted HIRA- and CAF-1-dependent reassembly. Elife 5, 94. doi:10.7554/eLife.15129

Lin, C.-J., Conti, M., Ramalho-Santos, M., 2013. Histone variant H3.3 maintains a decondensed chromatin state essential for mouse preimplantation development. Development 140, 3624-3634. doi:10.1242/dev.095513

Liu, Z., Tardat, M., Gill, M.E., Royo, H., Thierry, R., Ozonov, E.A., Peters, A.H., 2020. SUMOylated PRC1 controls histone $\mathrm{H} 3.3$ deposition and genome integrity of embryonic heterochromatin. The EMBO Journal e103697. doi:10.15252/embj.2019103697

Loyola, A., Tagami, H., Bonaldi, T., Roche, D., Quivy, J.-P., Imhof, A., Nakatani, Y., Dent, S.Y.R., Almouzni, G., 2009. The HP1alpha-CAF1-SetDB1-containing complex provides 
H3K9me1 for Suv39-mediated K9me3 in pericentric heterochromatin. EMBO Rep. 10, 769-775. doi:10.1038/embor.2009.90

Lu, J.Y., Chang, L., Li, T., Wang, T., Yin, Y., Zhan, G., Han, X., Zhang, K., Tao, Y., Percharde, M., Wang, L., Peng, Q., Yan, P., Zhang, H., Bi, X., Shao, W., Hong, Y., Wu, Z., Ma, R., Wang, P., Li, W., Zhang, J., Chang, Z., Hou, Y., Zhu, B., Ramalho-Santos, M., Li, P., Xie, W., Na, J., Sun, Y., Shen, X., 2021. Homotypic clustering of L1 and B1/Alu repeats compartmentalizes the 3D genome. Cell Res. 1, 26. doi:10.1038/s41422-020-00466-6

Luciani, J.J., Depetris, D., Usson, Y., Metzler-Guillemain, C., Mignon-Ravix, C., Mitchell, M.J., Megarbane, A., Sarda, P., Sirma, H., Moncla, A., Feunteun, J., Mattei, M.-G., 2006. PML nuclear bodies are highly organised DNA-protein structures with a function in heterochromatin remodelling at the G2 phase. Journal of Cell Science 119, 2518-2531. doi:10.1242/jcs.02965

Luijsterburg, M.S., de Krijger, I., Wiegant, W.W., Shah, R.G., Smeenk, G., de Groot, A.J.L., Pines, A., Vertegaal, A.C.O., Jacobs, J.J.L., Shah, G.M., van Attikum, H., 2016. PARP1 Links CHD2-Mediated Chromatin Expansion and H3.3 Deposition to DNA Repair by Nonhomologous End-Joining. Molecular Cell 61, 547-562. doi:10.1016/j.molcel.2016.01.019

Maeder, M.L., Angstman, J.F., Richardson, M.E., Linder, S.J., Cascio, V.M., Tsai, S.Q., Ho, Q.H., Sander, J.D., Reyon, D., Bernstein, B.E., Costello, J.F., Wilkinson, M.F., Joung, J.K., 2013. Targeted DNA demethylation and activation of endogenous genes using programmable TALE-TET1 fusion proteins. Nat Biotechnol 31, 1137-1142. doi:10.1038/nbt.2726

Mansuroglu, Z., Benhelli-Mokrani, H., Marcato, V., Sultan, A., Violet, M., Chauderlier, A., Delattre, L., Loyens, A., Talahari, S., Bégard, S., Nesslany, F., Colin, M., Souès, S., Lefebvre, B., Buée, L., Galas, M.-C., Bonnefoy, E., 2016. Loss of Tau protein affects the structure, transcription and repair of neuronal pericentromeric heterochromatin. Sci Rep 6, 33047. doi:10.1038/srep33047

Martens, J.H.A., O'Sullivan, R.J., Braunschweig, U., Opravil, S., Radolf, M., Steinlein, P., Jenuwein, T., 2005. The profile of repeat-associated histone lysine methylation states in the mouse epigenome. The EMBO Journal 24, 800-812. doi:10.1038/sj.emboj.7600545

Matsui, T., Leung, D., Miyashita, H., Maksakova, I.A., Miyachi, H., Kimura, H., Tachibana, M., Lorincz, M.C., Shinkai, Y., 2010. Proviral silencing in embryonic stem cells requires the histone methyltransferase ESET. Nature 464, 927-931. doi:10.1038/nature08858

Michaelson, J.S., Bader, D., Kuo, F., Kozak, C., Leder, P., 1999. Loss of Daxx, a promiscuously interacting protein, results in extensive apoptosis in early mouse development. Genes \& Development 13, 1918-1923.

Miyanari, Y., Ziegler-Birling, C., Torres-Padilla, M.-E., 2013. Live visualization of chromatin dynamics with fluorescent TALEs. Nat Biotechnol 20, 1321-1324. doi:10.1038/nsmb.2680

Mouse Genome Sequencing Consortium, Waterston, R.H., Lindblad-Toh, K., Birney, E., Rogers, J., Abril, J.F., Agarwal, P., Agarwala, R., Ainscough, R., Alexandersson, M., An, P., Antonarakis, S.E., Attwood, J., Baertsch, R., Bailey, J., Barlow, K., Beck, S., Berry, E., Birren, B., Bloom, T., Bork, P., Botcherby, M., Bray, N., Brent, M.R., Brown, D.G., Brown, S.D., Bult, C., Burton, J., Butler, J., Campbell, R.D., Carninci, P., Cawley, S., Chiaromonte, F., Chinwalla, A.T., Church, D.M., Clamp, M., Clee, C., Collins, F.S., Cook, L.L., Copley, R.R., Coulson, A., Couronne, O., Cuff, J., Curwen, V., Cutts, T., Daly, M., David, R., Davies, J., Delehaunty, K.D., Deri, J., Dermitzakis, E.T., Dewey, C., Dickens, N.J., Diekhans, M., Dodge, S., Dubchak, I., Dunn, D.M., Eddy, S.R., Elnitski, L., Emes, R.D., Eswara, P., Eyras, E., Felsenfeld, A., Fewell, G.A., Flicek, P., Foley, K., Frankel, W.N., Fulton, L.A., Fulton, R.S., Furey, T.S., Gage, D., Gibbs, R.A., Glusman, G., Gnerre, S., Goldman, N., Goodstadt, L., Grafham, D., Graves, T.A., Green, E.D., Gregory, S., Guigó, R., Guyer, M., Hardison, R.C., Haussler, D., Hayashizaki, Y., Hillier, L.W., Hinrichs, A., Hlavina, W., Holzer, T., Hsu, F., Hua, A., Hubbard, T., Hunt, A., Jackson, I., Jaffe, D.B., Johnson, L.S., Jones, M., Jones, T.A., Joy, A., Kamal, M., Karlsson, E.K., Karolchik, D., Kasprzyk, A., Kawai, J., Keibler, E., Kells, C., Kent, W.J., Kirby, A., Kolbe, D.L., Korf, I., Kucherlapati, R.S., Kulbokas, E.J., Kulp, D., Landers, T., Leger, J.P., Leonard, S., Letunic, I., Levine, R., Li, J., Li, M., Lloyd, C., Lucas, S., Ma, B., Maglott, D.R., Mardis, E.R., 
Matthews, L., Mauceli, E., Mayer, J.H., McCarthy, M., McCombie, W.R., McLaren, S., McLay, K., McPherson, J.D., Meldrim, J., Meredith, B., Mesirov, J.P., Miller, W., Miner, T.L., Mongin, E., Montgomery, K.T., Morgan, M., Mott, R., Mullikin, J.C., Muzny, D.M., Nash, W.E., Nelson, J.O., Nhan, M.N., Nicol, R., Ning, Z., Nusbaum, C., O'Connor, M.J., Okazaki, Y., Oliver, K., Overton-Larty, E., Pachter, L., Parra, G., Pepin, K.H., Peterson, J., Pevzner, P., Plumb, R., Pohl, C.S., Poliakov, A., Ponce, T.C., Ponting, C.P., Potter, S., Quail, M., Reymond, A., Roe, B.A., Roskin, K.M., Rubin, E.M., Rust, A.G., Santos, R., Sapojnikov, V., Schultz, B., Schultz, J., Schwartz, M.S., Schwartz, S., Scott, C., Seaman, S., Searle, S., Sharpe, T., Sheridan, A., Shownkeen, R., Sims, S., Singer, J.B., Slater, G., Smit, A., Smith, D.R., Spencer, B., Stabenau, A., Stange-Thomann, N., Sugnet, C., Suyama, M., Tesler, G., Thompson, J., Torrents, D., Trevaskis, E., Tromp, J., Ucla, C., Ureta-Vidal, A., Vinson, J.P., Niederhausern, Von, A.C., Wade, C.M., Wall, M., Weber, R.J., Weiss, R.B., Wendl, M.C., West, A.P., Wetterstrand, K., Wheeler, R., Whelan, S., Wierzbowski, J., Willey, D., Williams, S., Wilson, R.K., Winter, E., Worley, K.C., Wyman, D., Yang, S., Yang, S.-P., Zdobnov, E.M., Zody, M.C., Lander, E.S., 2002. Initial sequencing and comparative analysis of the mouse genome. Nature 420, 520-562. doi:10.1038/nature01262

Nakatani, T., Yamagata, K., Kimura, T., Oda, M., Nakashima, H., Hori, M., Sekita, Y., Arakawa, T., Nakamura, T., Nakano, T., 2015. Stella preserves maternal chromosome integrity by inhibiting 5hmC-induced $\mathrm{yH} 2 \mathrm{AX}$ accumulation. EMBO Rep. 16, 582-589. doi:10.15252/embr.201439427

Park, J., Lee, H., Han, N., Kwak, S., Lee, H.-T., Kim, J.-H., Kang, K., Youn, B.H., Yang, J.-H., Jeong, H.-J., Kang, J.-S., Kim, S.-Y., Han, J.-W., Youn, H.-D., Cho, E.-J., 2018. Long noncoding RNA ChRO1 facilitates ATRX/DAXX-dependent H3.3 deposition for transcriptionassociated heterochromatin reorganization. Nucleic Acids Res. 46, 11759-11775. doi:10.1093/nar/gky923

Peters, A.H., O'Carroll, D., Scherthan, H., Mechtler, K., Sauer, S., Schöfer, C., Weipoltshammer, K., Pagani, M., Lachner, M., Kohlmaier, A., Opravil, S., Doyle, M., Sibilia, M., Jenuwein, T., 2001. Loss of the Suv39h histone methyltransferases impairs mammalian heterochromatin and genome stability. Cell 107, 323-337. doi:10.1016/s00928674(01)00542-6

Pinheiro, I., Margueron, R., Shukeir, N., Eisold, M., Fritzsch, C., Richter, F.M., Mittler, G., Genoud, C., Goyama, S., Kurokawa, M., Son, J., Reinberg, D., Lachner, M., Jenuwein, T., 2012. Prdm3 and Prdm16 are H3K9me1 methyltransferases required for mammalian heterochromatin integrity. Cell 150, 948-960. doi:10.1016/j.cell.2012.06.048

Probst, A.V., Okamoto, I., Casanova, M., Marjou, El, F., Le Baccon, P., Almouzni, G., 2010. A strand-specific burst in transcription of pericentric satellites is required for chromocenter formation and early mouse development. Developmental Cell 19, 625-638. doi:10.1016/j.devcel.2010.09.002

Ran, F.A., Hsu, P.D., Wright, J., Agarwala, V., Scott, D.A., Zhang, F., 2013. Genome engineering using the CRISPR-Cas9 system. Nat Protoc 8, 2281-2308. doi:10.1038/nprot.2013.143

Sadic, D., Schmidt, K., Groh, S., Kondofersky, I., Ellwart, J., Fuchs, C., Theis, F.J., Schotta, G., 2015. Atrx promotes heterochromatin formation at retrotransposons. EMBO Rep. 16, 836-850. doi:10.15252/embr.201439937

Saksouk, N., Barth, T.K., Ziegler-Birling, C., Olova, N., Nowak, A., Rey, E., Mateos-Langerak, J., Urbach, S., Reik, W., Torres-Padilla, M.-E., Imhof, A., Déjardin, J., Simboeck, E., 2014. Redundant mechanisms to form silent chromatin at pericentromeric regions rely on BEND3 and DNA methylation. Molecular Cell 56, 580-594. doi:10.1016/j.molcel.2014.10.001

Salsman, J., Rapkin, L.M., Margam, N.N., Duncan, R., Bazett-Jones, D.P., Dellaire, G., 2017. Myogenic differentiation triggers PML nuclear body loss and DAXX relocalization to chromocentres. Cell Death Dis 8, e2724. doi:10.1038/cddis.2017.151 
Song, Y.J., Choi, J.H., Lee, H., 2015. Setdb1 is required for myogenic differentiation of C2C12 myoblast cells via maintenance of MyoD expression. Mol Cells 38, 362-372. doi:10.14348/molcells.2015.2291

Strom, A.R., Emelyanov, A.V., Mir, M., Fyodorov, D.V., Darzacq, X., Karpen, G.H., 2017. Phase separation drives heterochromatin domain formation. Nature 547, 241-245. doi:10.1038/nature22989

Szenker, E., Ray-Gallet, D., Almouzni, G., 2011. The double face of the histone variant H3.3. Cell Res. 21, 421-434. doi:10.1038/cr.2011.14

Therizols, P., Illingworth, R.S., Courilleau, C., Boyle, S., Wood, A.J., Bickmore, W.A., 2014. Chromatin decondensation is sufficient to alter nuclear organization in embryonic stem cells. Science 346, 1238-1242. doi:10.1126/science.1259587

Tosolini, M., Brochard, V., Adenot, P., Chebrout, M., Grillo, G., Navia, V., Beaujean, N., Francastel, C., Bonnet-Garnier, A., Jouneau, A., 2018. Contrasting epigenetic states of heterochromatin in the different types of mouse pluripotent stem cells. Sci Rep 8, 5776. doi:10.1038/s41598-018-23822-4

Walter, M., Teissandier, A., Pérez-Palacios, R., Bourc'his, D., 2016. An epigenetic switch ensures transposon repression upon dynamic loss of DNA methylation in embryonic stem cells. Elife 5, R87. doi:10.7554/eLife.11418

Wang, L., Gao, Y., Zheng, X., Liu, C., Dong, S., Li, R., Zhang, G., Wei, Y., Qu, H., Li, Y., Allis, C.D., Li, G., Li, H., Li, P., 2019. Histone Modifications Regulate Chromatin Compartmentalization by Contributing to a Phase Separation Mechanism. Molecular Cell 76, 646-659.e6. doi:10.1016/j.molcel.2019.08.019

Wossidlo, M., Nakamura, T., Lepikhov, K., Marques, C.J., Zakhartchenko, V., Boiani, M., Arand, J., Nakano, T., Reik, W., Walter, J., 2011. 5-Hydroxymethylcytosine in the mammalian zygote is linked with epigenetic reprogramming. Nat Commun 2, 241. doi:10.1038/ncomms 1240

Ying, Q.-L., Wray, J., Nichols, J., Batlle-Morera, L., Doble, B., Woodgett, J., Cohen, P., Smith, A., 2008. The ground state of embryonic stem cell self-renewal. Nature 453, 519-523. doi:10.1038/nature06968

Young, L.C., McDonald, D.W., Hendzel, M.J., 2013. Kdm4b histone demethylase is a DNA damage response protein and confers a survival advantage following $\mathrm{Y}$-irradiation. Journal of Biological Chemistry 288, 21376-21388. doi:10.1074/jbc.M113.491514

Zhu, Q., Pao, G.M., Huynh, A.M., Suh, H., Tonnu, N., Nederlof, P.M., Gage, F.H., Verma, I.M., 2011. BRCA1 tumour suppression occurs via heterochromatin-mediated silencing. Nature 477, 179-184. doi:10.1038/nature10371

Ziegler-Birling, C., Helmrich, A., Tora, L., Torres-Padilla, M.-E., 2009. Distribution of p53 binding protein 1 (53BP1) and phosphorylated H2A.X during mouse preimplantation development in the absence of DNA damage. Int. J. Dev. Biol. 53, 1003-1011. doi:10.1387/ijdb.082707cz 


\section{Legends}

Figure 1/ DAXX is essential for ESC survival upon ground-state conversion. (A) Schematic of the Daxx locus and the sequence of the small guide RNA targeting exon 3. RTqPCR experiment displaying mean of two biological replicates with SEM. Western blot corresponds to one experiment from at least 2 biological replicates. (B) Quantification of the number of cells compared to WT in each culture condition. Histogram represents mean with SEM of 3 biological replicates for each condition except Diff. which is the mean of two biological replicates. (C) Dot blot using $5 \mathrm{mC}$ antibody to assess global DNA methylation levels upon $2 \mathrm{i}+\mathrm{VitC}$ conversion. One experiment is shown. Histogram displays mean with SEM from 3 independent replicates. (D) Volcano plots representing the number of differentially expressed genes upon $2 \mathrm{i}+\mathrm{VitC}$ conversion of WT and Daxx KO ESCs. Previously identified 2i+VitC conversion markers are in red for up-regulated or blue for down-regulated (Blaschke et al., 2013). T-tests were used for statistical analysis in B.

Figure 2 | DAXX relocates to chromocenters after DNA damage upon ground-state conversion. (A) Representative immunofluorescence pictures showing DAXX and PML in $2 \mathrm{i}+\mathrm{VitC}$, serum-base or differentiated conditions with or without $2 \mathrm{mM} \mathrm{HU}$ treatment, as indicated. White dashed square highlights a DAXX-PML structure at $\mathrm{PCH}$ in $2 \mathrm{i}+\mathrm{VitC}$ and 'classical' PML NBs in serum and differentiated cells. (B) Quantification of the mean number of DAXX-PML structures observed at $\mathrm{PCH}$ upon $2 \mathrm{i}+\mathrm{VitC}$ conversion or in serum-based or differentiated conditions with or without $2 \mathrm{mM} \mathrm{HU}$ treatment displayed in $\mathrm{A}$. $\mathrm{n}=$ total number of nuclei analyzed from at least 2 biological replicates. (C) Immunofluorescence of yH2AX in WT ESCs in serum, $2 \mathrm{i}+\mathrm{VitC}$ and differentiated conditions. Histogram displays the number of yH2AX foci observed to colocalize to DAPI-dense chromocenters. $n=$ total number of nuclei analyzed from at least 3 biological replicates. (D) Representative immunofluorescence pictures of DAXX and PML or $\mathrm{yH} 2 \mathrm{AX}$ and PML in WT transfected cells with either a catalytically dead Cas9 (dCas9) or an active Cas9 and a small RNA guide targeting Major Satellites. Histogram indicates mean number of DAXX-PML structures at PCH with SEM. $n=$ total number of nuclei 
analyzed from at least 2 biological replicates. Chi-square tests were used for statistical analysis in $B, C$ and $D$.

Figure 3 | Active DNA demethylation causes DNA damage in embryonic stem cells. (A) Representative immunofluorescence pictures of H3K9me3, DAXX and PML in serum or $2 \mu \mathrm{M}$ 5-azacytidine-treated cells. White dashed square highlights DAXX-PML NB. Bottom, quantification of the number of DAXX-PML structures at $\mathrm{PCH}$ observed in each condition. Histogram represents the mean with SEM of 3 biological replicates. $n=$ total number of nuclei analyzed. (B) Quantification of the number of cells compared to WT in serum-based medium or after $2 \mu \mathrm{M}$ 5-azacytidine treatment. Histogram represents the mean with SEM of 3 biological replicates. (C) Left, representative immunofluorescence pictures showing $\mathrm{yH} 2 \mathrm{AX}$ and Flag in WT transfected cells with either TALE $\mathrm{MajSat} \Delta$ or TALE $\mathrm{MajSat} \mathrm{TET} 1 \mathrm{CD}$. Right, quantification of the number of $\mathrm{yH} 2 \mathrm{AX}$ foci observed above DAPI-dense chromocenters. Histogram represents mean with SEM of two biological replicates. $n=$ total number of nuclei analyzed. Chi-square tests were used for statistical analysis. (D) Representative immunofluorescence pictures of $5 \mathrm{mC}$ staining for WT serum ESCs transfected with $\mathrm{TALE}_{\text {MajSat }} \Delta$ or TALE $\mathrm{MajSat}$ TET1CD. Right, measurements of the intensity profiles of individual DAPI-dense chromocenters for either $5 \mathrm{mC}$ (left) or DAPI (right) signals. $\mathrm{n}=$ total number of chromocenter analyzed from 2 biological replicates. 5-aza $=5$-azacytidine. Chi-square tests were used for statistical analysis in $\mathrm{A}$ and C. T-tests were used for statistical analysis in B.

Figure 4 | DAXX maintains heterochromatin organization in pluripotent cells. (A) Left, representative major satellite DNA FISH pictures of WT and Daxx KO ESCs in serum or in $2 i+V i t C$. Right, quantification of the number of major satellite foci counted on focal plane. $\mathrm{n}=$ total number of nuclei analyzed from at least 3 biological replicates. (B) Top, representative immunoFISH pictures of major satellite and Flag for Daxx KO cells transfected with TALE MajSat- $^{-}$ $\Delta$ or TALE $E_{\text {MajSat }}-D A X X$. Bottom left, quantification of the number of major satellite foci detected in focal plane. Bottom right, quantification of the surface of each major satellite foci analyzed. Area was measured for each focus detected on medium focal plane. $n=$ total number of nuclei 
analyzed from 4 biological replicates. (C) Top, scheme depicting the two different analysis used in our live-imaging experiments. Bottom, representative pictures from FRAP experiments performed on WT and Daxx KO cells transfected with GFP-HP1 1 . T=-5" corresponds to prebleach fluorescence. $T=0$ corresponds to the laser bleach pulse. $T=4$ and 23 " correspond to post-bleach recovery images. Right, quantification of half-recovery times for individual nuclei. $\mathrm{n}=$ total number of nuclei analyzed from 2 biological replicates. (D) Left, representative pictures of GFP-HP1 $\alpha$ and corresponding variance in fluorescence intensities along time in serumbased or $2 i+V i t C$ WT or Daxx KO ESCs. White dashed squares display magnification of individual chromocenters and the $1 \mu \mathrm{m}$ line drawn in grey. Right, graph displaying the variance intensities along a $1 \mu \mathrm{m}$ line traced above non-bleached chromocenters. Two-sided MannWhitney tests were used for statistical analysis in A, B and C.

Figure 5 | DAXX recruits Setdb1 and mediates chromocenter clustering via H3.3K9me3 modification. (A) Left, representative immunofluorescence pictures for SETDB1, DAXX and PML in WT or Daxx KO ESCs upon $2 \mathrm{i}+\mathrm{VitC}$ conversion. Right, quantification of the mean number of PML or SETDB1 foci at chromocenters in WT and Daxx KO ESCs. White arrow indicates an example of DAXX-PML-SETDB1 structure at $\mathrm{PCH} . \mathrm{n}=$ total number of nuclei analyzed from two independent replicates. (B) Top, representative immunoFISH pictures for H3K9me3, PML and major satellites in ground-state and serum Suv39H1/2 dKO ESCs. White dashed squares highlight a major satellite focus. Bottom, fluorescence intensity profile highlighting structure within the white dashed squares. White arrow indicates an example of DAXX-PML structure at $\mathrm{PCH}$ upon $2 \mathrm{i}+\mathrm{VitC}$ conversion. (C) Representative immunofluorescence pictures for H3K9me3 and Flag in Suv39dKO serum ESCs transfected

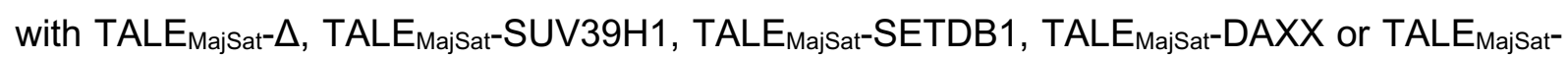
$D X^{Y 222 A}$. (D) Quantification of the percentage of cells displaying H3K9me3 recruitment at Flag-DAPI-dense chromocenters. (E) Quantification of the number of Flag foci observed from C. (F) Left, representative immunoFISH pictures for major satellite and Flag in Daxx KO serum

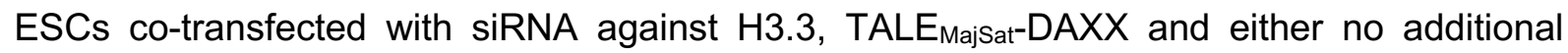


construct or H3.3WT, H3.3G90M or H3.3K9A. Right, quantification of the number of major satellite foci detected of medium focal plane. For comparison, distribution $T_{M S}-D A X X$ without H3.3 knockdown data comes from Figure 4B. n=total number of nuclei analyzed from 2 biological replicates. Chi-square tests were used for statistical analysis in A. T-tests were used for statistical analysis in D. Two-sided Mann-Whitney tests were used for statistical analysis in $E$ and $F$.

Figure 6 | Model for heterochromatin maintenance by DAXX in ESCs. (A) Upon groundstate conversion, active DNA demethylation induced by the TET enzymes can result into DNA double-strand breaks at chromocenters. In response to DNA damages, DAXX accumulates at chromocenters and is surrounded by a PML shell. DAXX can then recruit the histone methyltransferase SETDB1 to promote $\mathrm{H} 3.3 \mathrm{~K} 9 \mathrm{me} 3$ to maintain the pericentromeric heterochromatin. (B) In Daxx KO cells, the physical properties, and the 3D-organization of pericentromeric heterochromatin are impaired, leading to promiscuous expression of major satellites and preventing prolonged culture of these cells in ground-state condition. 
bioRxiv preprint doi: https://doi.org/10.1101/2021.04.28.441827: this version posted April 28, 2021. The copyright holder for this preprint (which was not certified by peer review) is the author/funder, who has granted bioRxiv a license to display the preprint in perpetuity. It is made available under aCC-BY-NC-ND 4.0 International license.

\section{Figure 1}

A

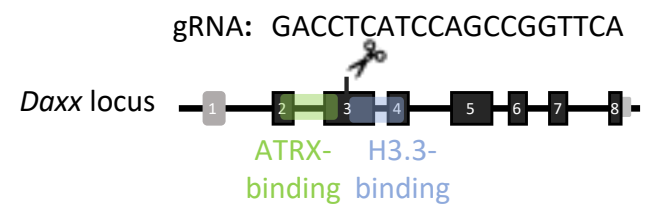

\section{Daxx mRNA expression}

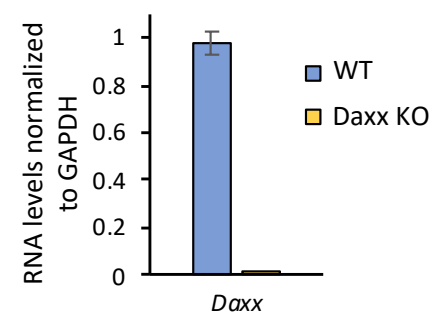

C

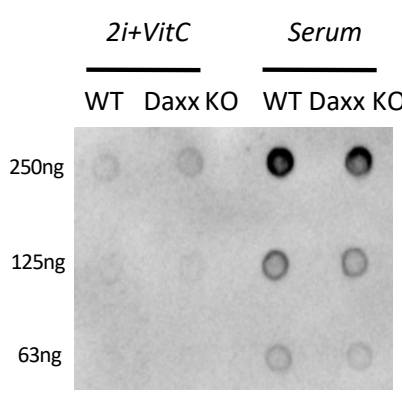

Global DNA methylation

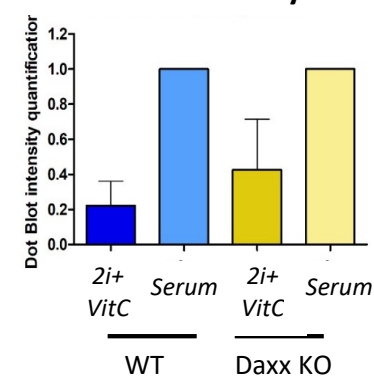

D
B
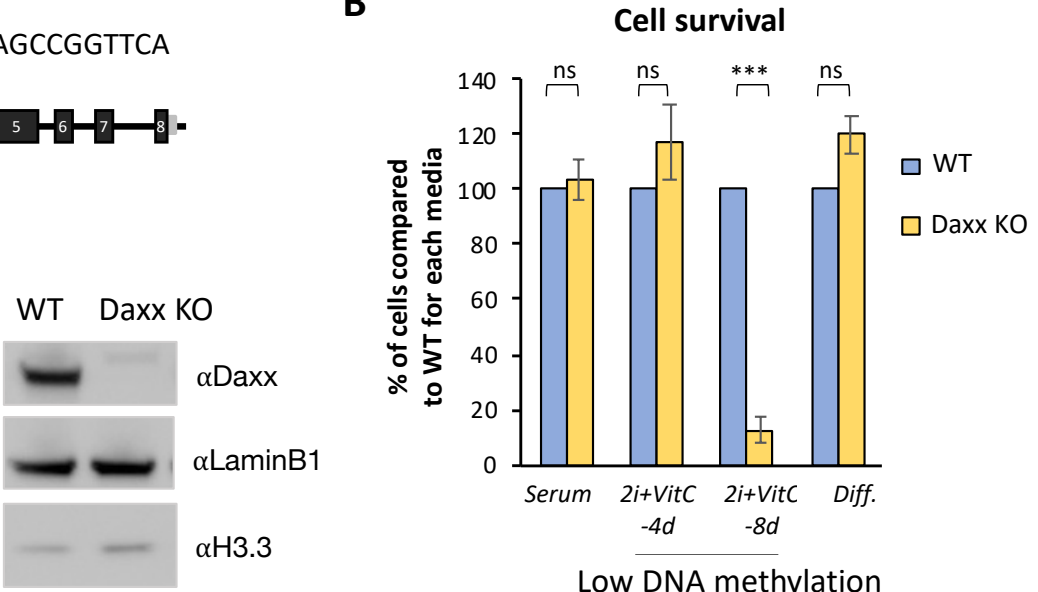

Low DNA methylation
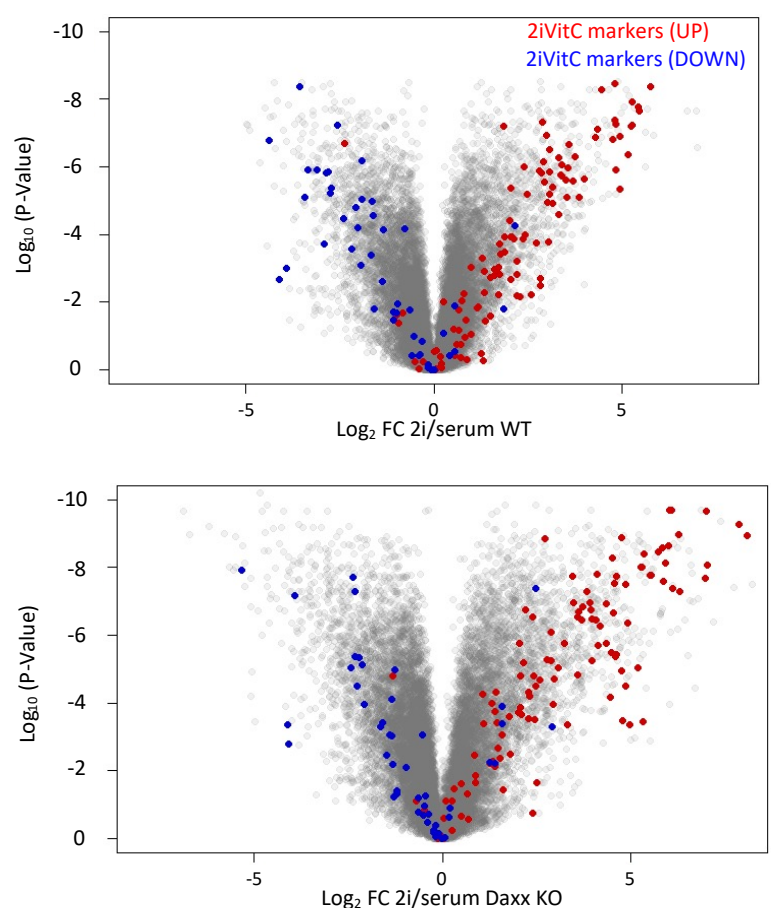
bioRxiv preprint doi: https://doi.org/10.1101/2021.04.28.441827; this version posted April 28, 2021. The copyright holder for this preprint (which was not certified by peer review) is the author/funder, who has granted bioRxiv a license to display the preprint in perpetuity. It is made available under aCC-BY-NC-ND 4.0 International license.

\section{Figure 2}

A
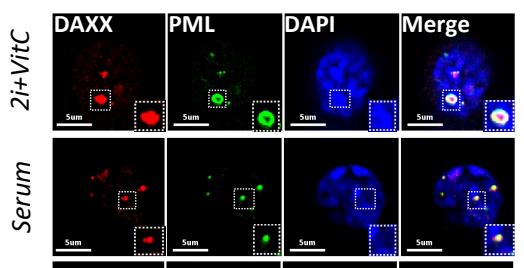

謇
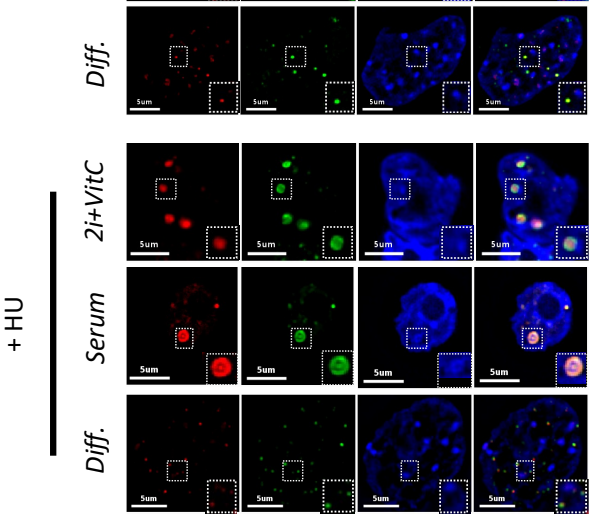

C

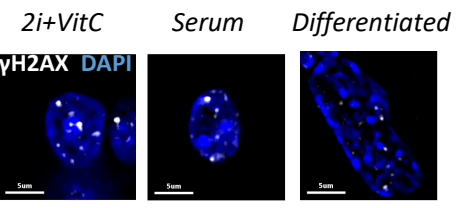

YH2AX-positive chromocenters

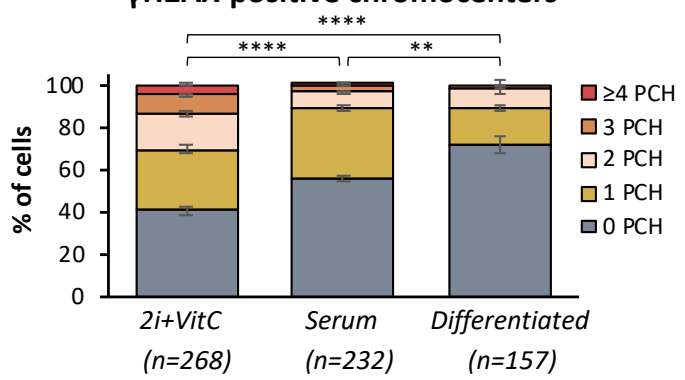

B

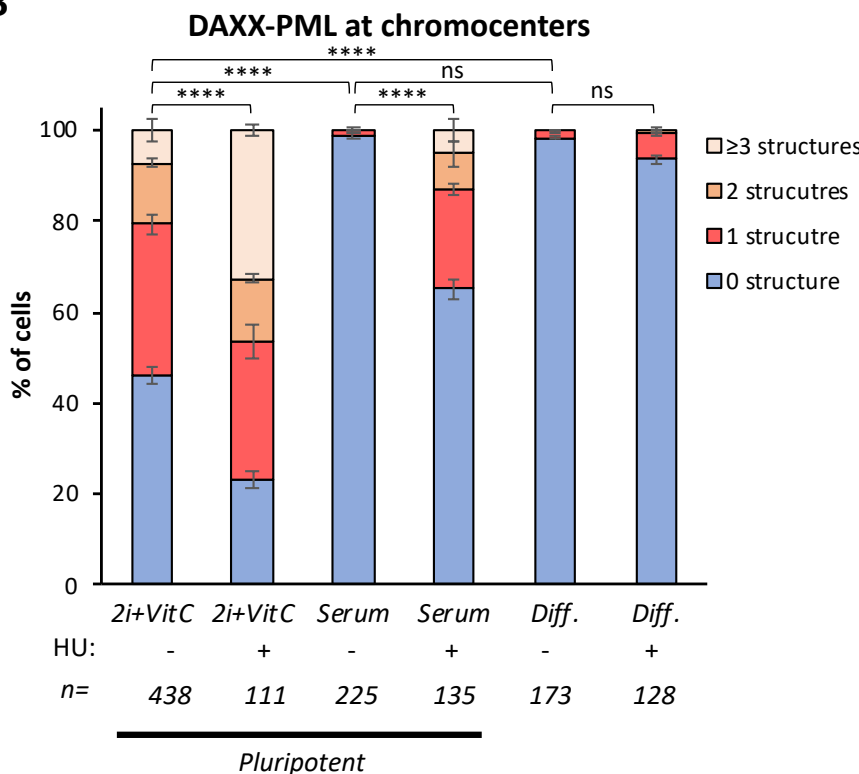

D

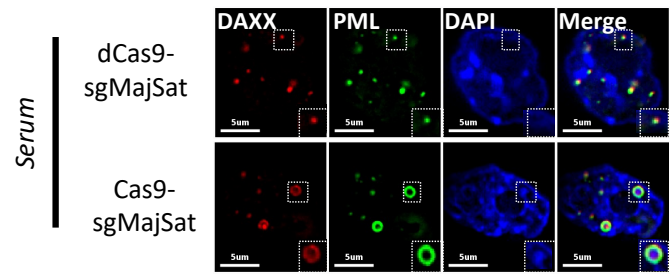

DAXX-PML at chromocenters

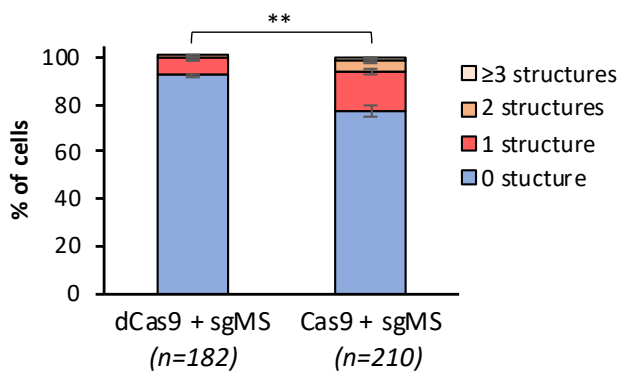


bioRxiv preprint doi: https://doi.org/10.1101/2021.04.28.441827; this version posted April 28, 2021. The copyright holder for this preprint

\section{Figure 3}

A

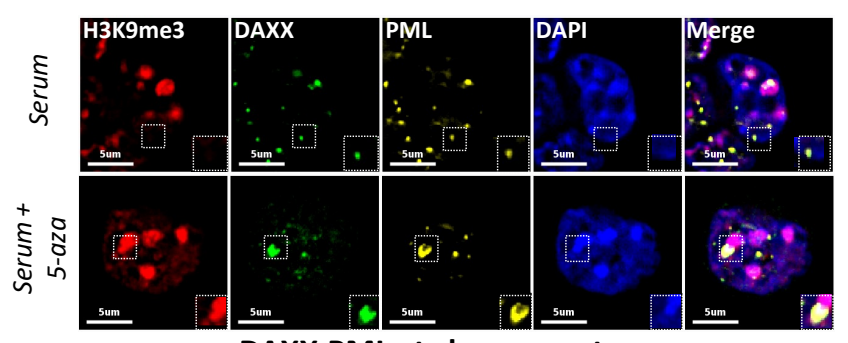

DAXX-PML at chromocenters

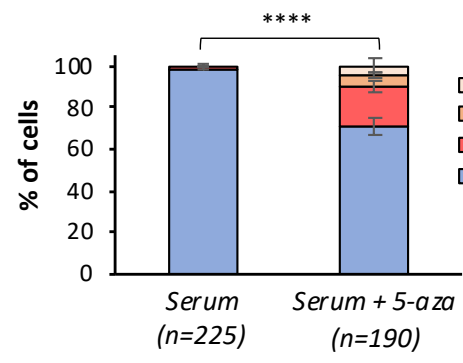

C

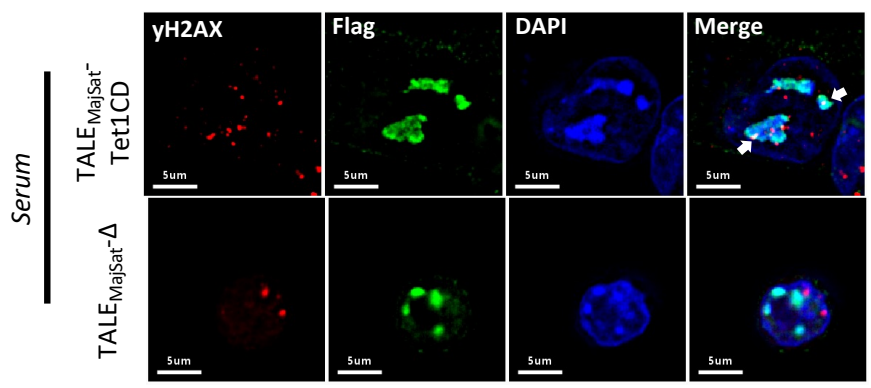

D

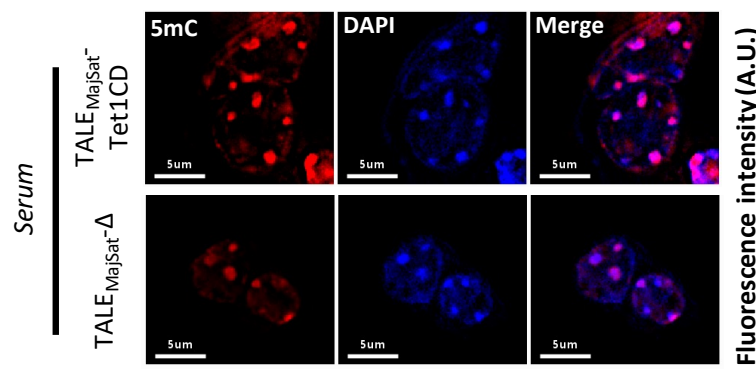

B

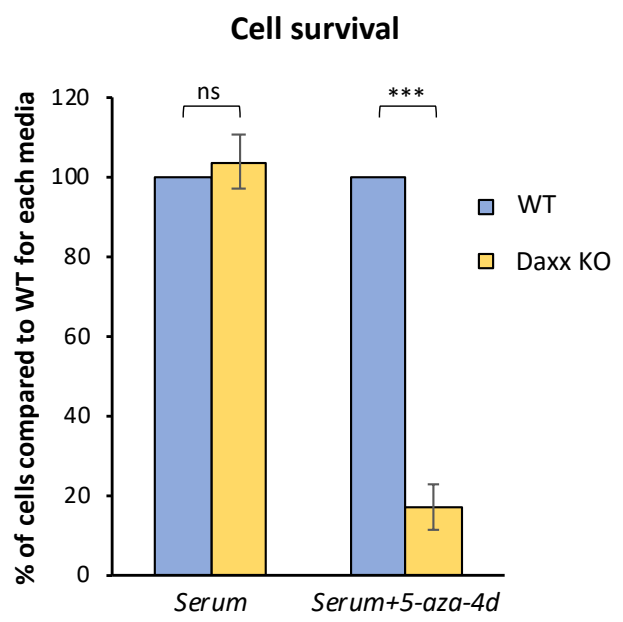

YH2AX-positive chromocenters

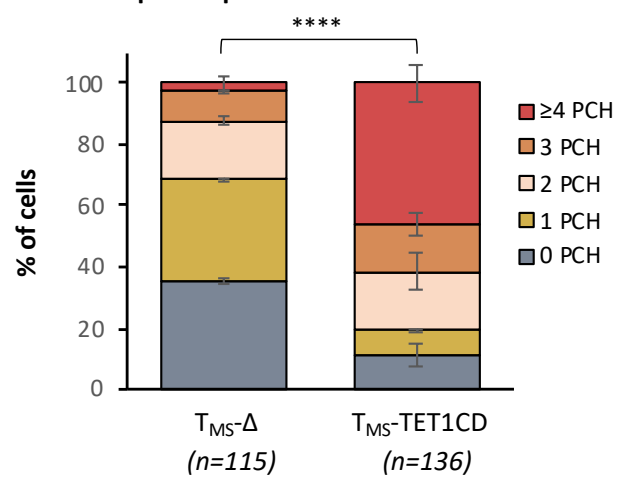

$5 \mathrm{mC}$ at chromocenters DAPI at chromocenters

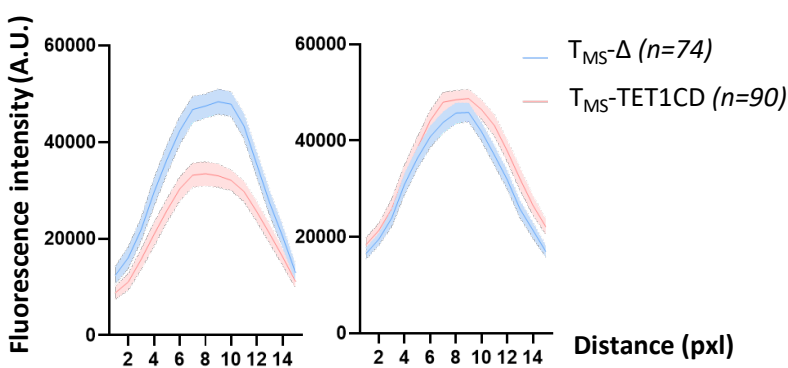


bioRxiv preprint doi: https://doi.org/10.1101/2021.04.28.441827; this version posted April 28, 2021. The copyright holder for this preprint (which was not certified by peer review) is the author/funder, who has granted bioRxiv a license to display the preprint in perpetuity. It is made available under aCC-BY-NC-ND 4.0 International license.

\section{Figure 4}

A

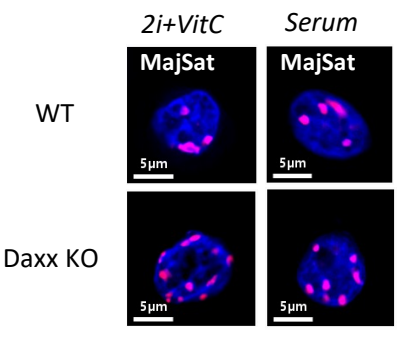

MajSat clustering

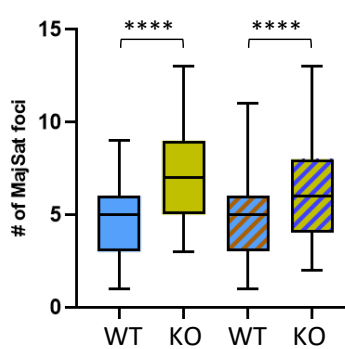

$n=\frac{253141}{2 i+\text { VitC }} \frac{220179}{\text { Serum }}$

B

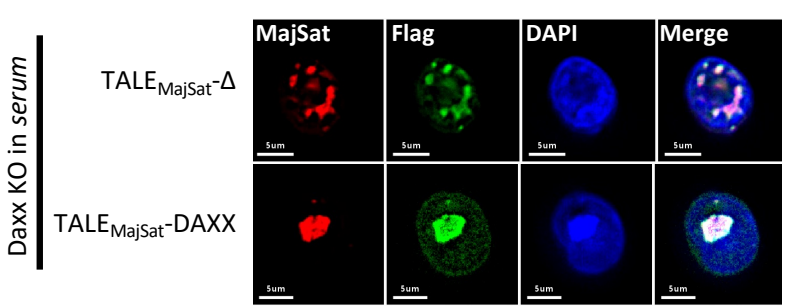

MajSat clustering

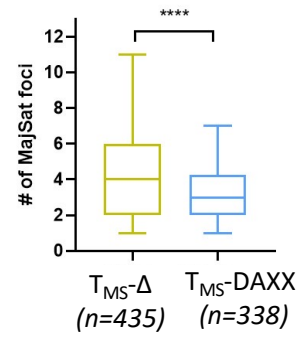

Size of MajSat foci

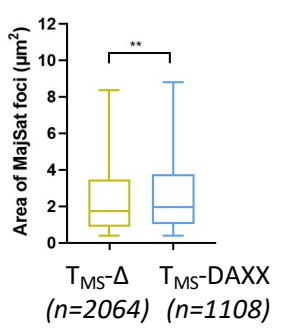

C

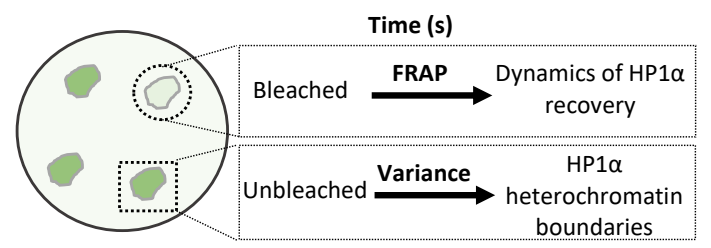

GFP-HP1 $\alpha$ recovery after photobleaching

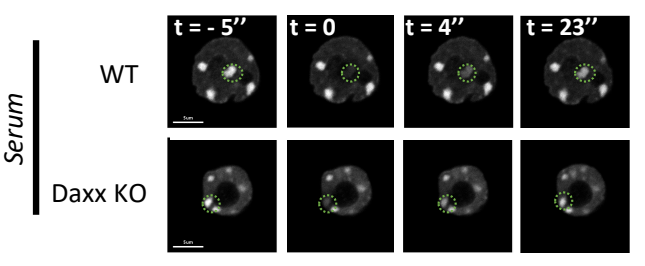

GFP-HP1 $\alpha$ half-recovery time

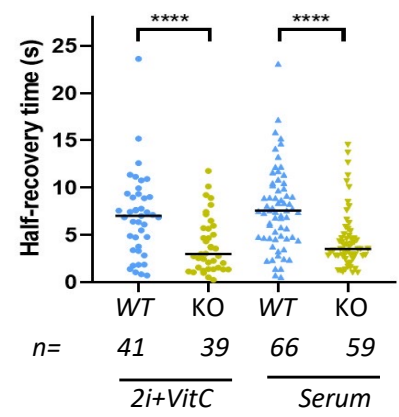

\section{D}

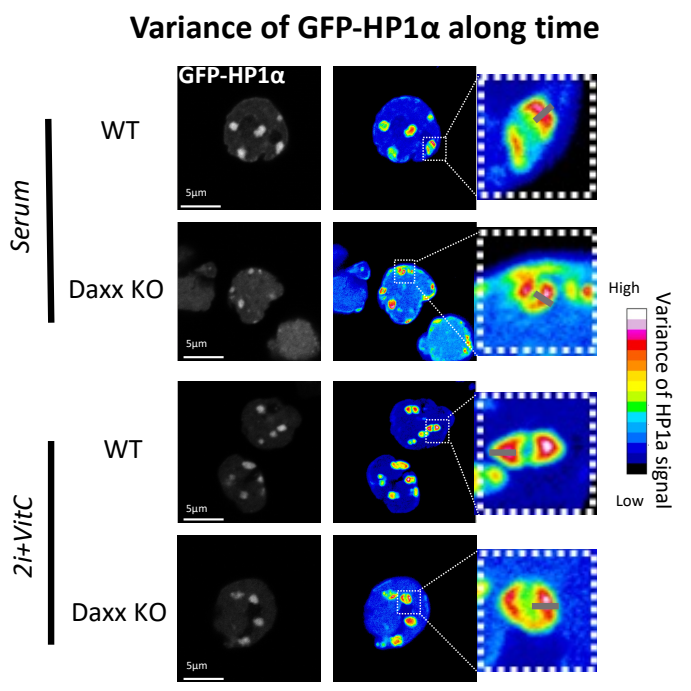

\section{GFP-HP1 $\alpha$ variance at chromocenters}
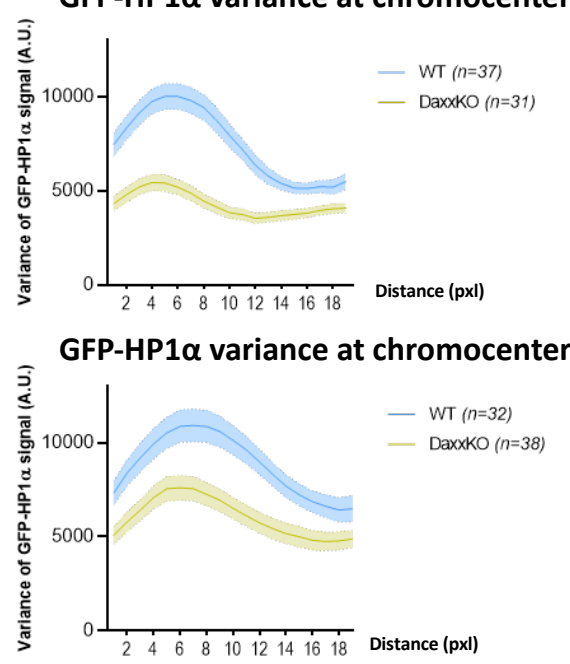
bioRxiv preprint doi: https://doi.org/10.1101/2021.04.28.441827; this version posted April 28, 2021. The copyright holder for this preprint (which was not certified by peer review) is the author/funder, who has granted bioRxiv a license to display the preprint in perpetuity. It is made available under aCC-BY-NC-ND 4.0 International license.

\section{Figure 5}

A

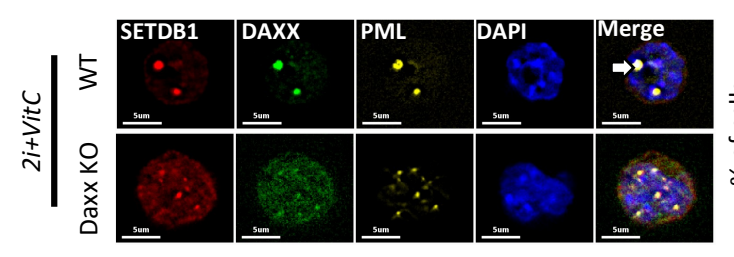

B
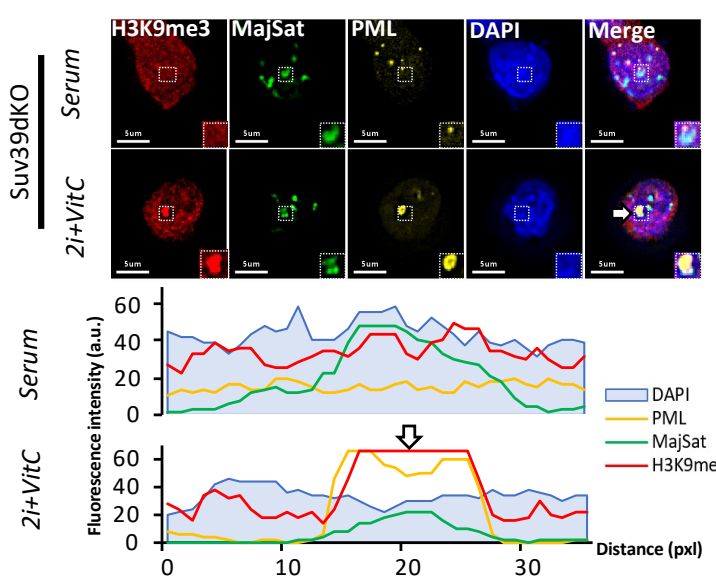

D

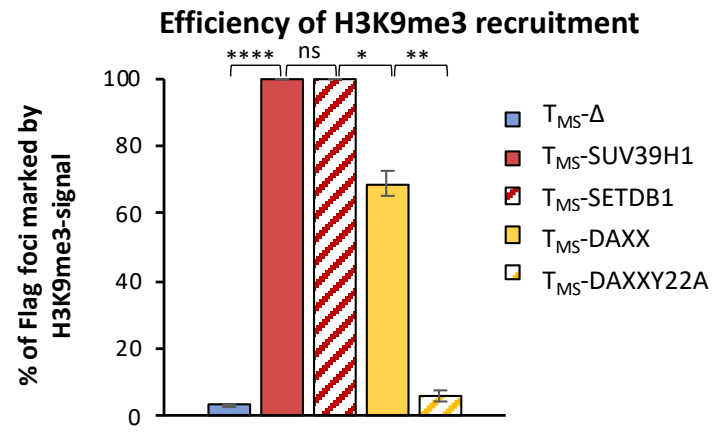

PML at chromocenters SETDB1 at chromocenters

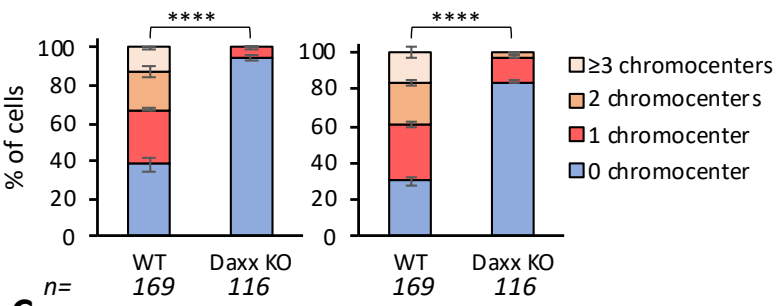

$\mathbf{C}^{n}$

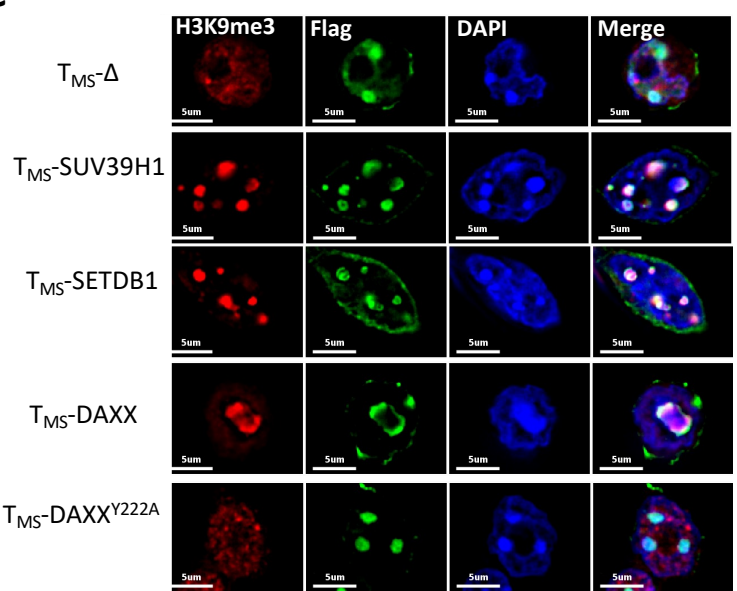

E

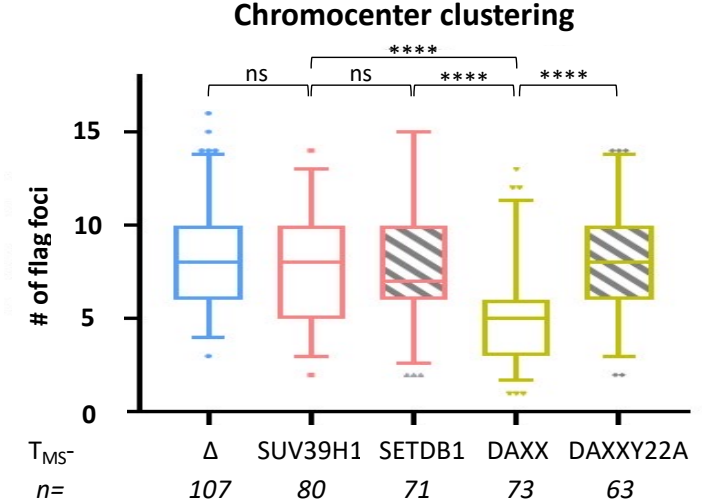

F
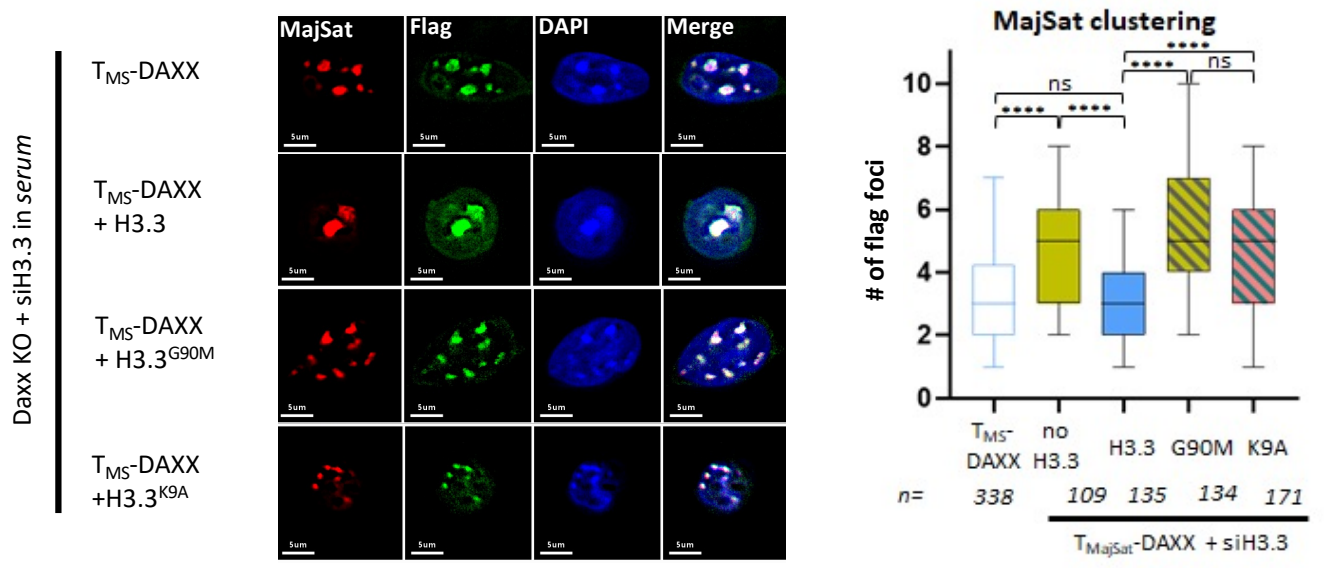
bioRxiv preprint doi: https://doi.org/10.1101/2021.04.28.441827; this version posted April 28, 2021. The copyright holder for this preprint (which was not certified by peer review) is the author/funder, who has granted bioRxiv a license to display the preprint in perpetuity. It is made available under aCC-BY-NC-ND 4.0 International license.

\section{Figure 6}

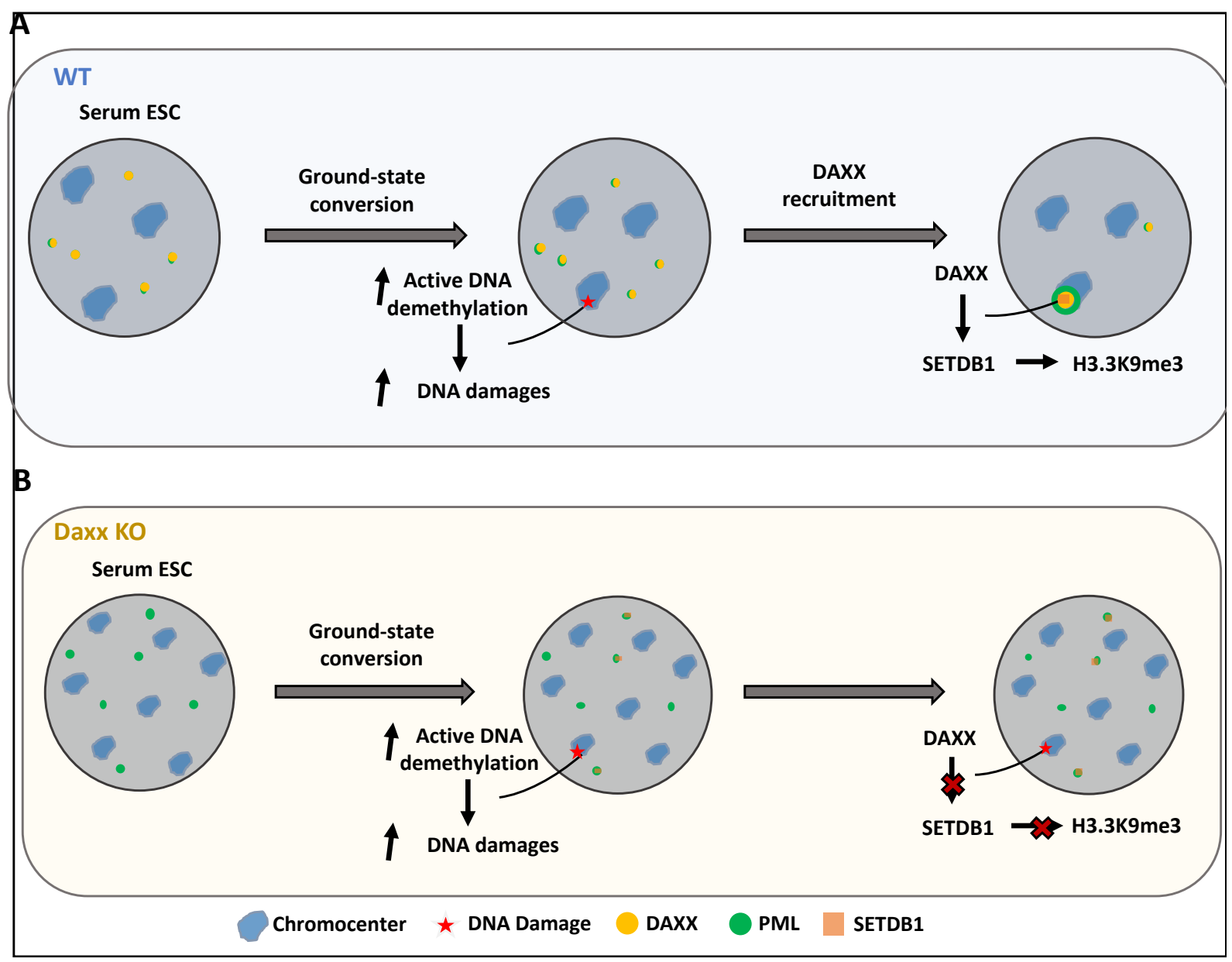

